\title{
Directed Biosynthesis of Alkaloid Analogs in the Medicinal Plant Catharanthus roseus
}

Elizabeth McCoy and Sarah E. O'Connor*

Massachusetts Institute of Technology, 77 Massachusetts Avenue, Cambridge, MA 02139 (617) 324-0180

\section{Supporting Information}

\section{Table of Contents}

1. Experimental Methods

2. Tabulated NMR data

3. ${ }^{1}$ HNMR Spectra

3.1. 10-fluoroserpentine, $5 \mathrm{c}$

3.2. 11 -fluoroserpentine, $5 \mathrm{~d}$

3.3. 12-methylserpentine, $5 \mathrm{e}$

3.4. 10-fluoroajmalicine, $4 \mathrm{c}$

3.5. 12-methylakuammicine, $8 \mathrm{e}$

3.6. COSY 12-methylakuammcine, $8 \mathbf{e}$

3.7. 11-fluoroakuammicine, $8 \mathrm{~d}$

4. High Resolution Mass Data

5. Extrapolated LC-MS traces of Alkaloid Extracts

5.1. 5-fluorotryptamine, c, hairy root extract: $\mathrm{m} / \mathrm{z} 367$ 5c

5.2. 5-fluorotryptamine, c, hairy root extract: $\mathrm{m} / \mathrm{z} 371$ 4c

5.3. 5-fluorotryptamine, c, hairy root extract: $\mathrm{m} / \mathrm{z} 373$ 6c

5.4. 6-fluorotryptamine, d, hairy root extract: $\mathrm{m} / \mathrm{z} 367$ 5d

5.5. 6-fluorotryptamine, $\mathbf{d}$, hairy root extract: $\mathrm{m} / \mathrm{z} 371$ 4d

5.6. 6-fluorotryptamine, d, hairy root extract: $\mathrm{m} / \mathrm{z} 373 \mathbf{6 d}$

5.7. 6-fluorotryptamine, d, hairy root extract: $\mathrm{m} / \mathrm{z} 341 \mathbf{8 d}$

5.8. 7-methyltryptamine, e, hairy root extract: $\mathrm{m} / \mathrm{z} 363 \mathbf{5 e}$

5.9. 7-methyltryptamine, e, hairy root extract: $\mathrm{m} / \mathrm{z} 367 \mathbf{4 e}$

5.10. 7-methyltryptamine, e, hairy root extract: $\mathrm{m} / \mathrm{z} 369$ 6e

5.11. 7-methyltryptamine, e, hairy root extract: $\mathrm{m} / \mathrm{z} 337 \mathbf{8 e}$

5.12. 5-hydroxytryptamine, $\mathbf{f}$, hairy root extract: $\mathrm{m} / \mathrm{z} 365 \mathbf{5 f}$

5.13. 5-fluorotryptamine, c, seedling extract: $\mathrm{m} / \mathrm{z} 44510 \mathrm{c}$

5.14. 5-fluorotryptamine, c, seedling extract: $\mathrm{m} / \mathrm{z} 475$ 2c

5.15. 5-fluorotryptamine, c, seedling extract: $\mathrm{m} / \mathrm{z} 371$ 4c

5.16. 5-fluorotryptamine, c, seedling extract: $\mathrm{m} / \mathrm{z} 355$

5.17. 6-fluorotryptamine, d, seedling extract: $\mathrm{m} / \mathrm{z} 367$ 5d

5.18. 6-fluorotryptamine, d, seedling extract: $\mathrm{m} / \mathrm{z} 445$ 10d

5.19. 10, 2, 10d, 2c fragmentation

5.20. 6-fluorotryptamine, d, seedling extract: $\mathrm{m} / \mathrm{z} 355$

5.21. 6-fluorotryptamine, d, seedling extract: $\mathrm{m} / \mathrm{z} 341$ 8d

5.22. 7-methyltryptamine, e, seedling extract: $\mathrm{m} / \mathrm{z} 367$ 4e

5.23. 7-methyltryptamine, e, seedling extract: $\mathrm{m} / \mathrm{z} 363$ 5e

5.24. 7-methyltryptamine, e, seedling extract: $\mathrm{m} / \mathrm{z} 369$ 6e

5.25. 7-methyltryptamine, e, seedling extract: $\mathrm{m} / \mathrm{z} 337 \mathbf{8 e}$

5.26. 7-methyltryptamine, e, seedling extract: $\mathrm{m} / \mathrm{z} 351$ 


\section{Experimental Methods}

\section{A. Seedling growth}

Tryptamine substrates $(\mathbf{a}-\mathbf{f})$ were dissolved in $500 \mu \mathrm{L} 0.27 \mathrm{~N} \mathrm{HCl}(100 \mathrm{mM})$, syringe filtered through a 0.2 $\mu \mathrm{m}$ filter to sterilize, and added to MS media with vitamins (Sigma) $(50 \mathrm{~mL}, \mathrm{pH}=5.7)$ with $2 \mathrm{~g} / \mathrm{L}$ phytogel. The $\mathrm{pH}$ of the media was adjusted to $\mathrm{pH} 5.7$ with $4 \mathrm{~N} \mathrm{KOH}(34 \mu \mathrm{L})$. The final concentration of analog in the media was $1 \mathrm{mM}$. The supplemented media was added to a square plate and allowed to solidify. $C$. roseus seeds (Horizon herbs) were sterilized for 30 seconds in ethanol, 10 minutes in $10 \%$ bleach, filtered under vacuum and washed 3 times with filter sterilized water. The seeds were then transplanted individually to the square grid Petri dish (36 seeds per plate), containing MS media with the indicated analog. Seedlings were grown in the dark for 7 days and then under incandescent light with 16 hours light and 8 hours dark for 10 days, yielding approximately $1 \mathrm{~g}$ of seedlings per plate. No growth inhibition was seen for analog compared to the control plates. Plant material was then collected and extracted as described below.

\section{B. Hairy root culture}

C. roseus hairy root cultures (provided by Prof. J. Shanks (lowa State) and Prof. Lee-Parsons (Northeastern)) were sub-cultured in $25 \mathrm{~mL}$ of half strength Gamborg's media and vitamins $(\mathrm{pH}=5.7)$ and grown for 7 days at $26^{\circ} \mathrm{C}$ shaking at $50 \mathrm{rpm}$. Tryptamine analogs (a-f) were dissolved in DMSO and were added to the media to a final concentration of $1 \mathrm{mM}$ on day 7 . Flasks of roots $(25 \mathrm{~mL})$ were cultured for an additional 14 days. Autoclaved water was added to the cultures weekly to account for evaporation. Roots were removed from the media, and both plant material and media were extracted as described below.

\section{Alkaloid Extraction}

One gram of fresh seedlings or roots was ground with a mortar and pestle in methanol $(3 \times 30 \mathrm{~mL})$. The methanol extract was filtered and concentrated under vacuum to yield a yellow solid. This solid was then sonicated for 30 minutes in $3 \%$ aqueous $\mathrm{HCl}$. The $\mathrm{HCl}$ solution was extracted with hexanes $(3 \times 30 \mathrm{~mL})$ to remove hydrophobic material. A solution of $\mathrm{NH}_{4} \mathrm{OH}$ was then used to adjust the $\mathrm{pH}$ of the solution to above 8 . The basic aqueous solution was then extracted with methylene chloride $(3 \times 30 \mathrm{~mL})$. The combined methylene chloride fractions were washed with brine, dried over sodium sulfate and concentrated to yield a yellow alkaloid extract $(2-10 \mathrm{mg})$. The extract was dissolved in methanol $(1 \mathrm{~mL})$ for further analysis by HPLC and LC-MS. The root media was adjusted to $\mathrm{pH} 8$ and extracted and concentrated as described for the roots. The media contained small quantities of the desired alkaloid analogs and presence in the media may be due to cell lysis.

\section{LC-MS analysis}

The alkaloid mixtures were diluted 1/1000 with methanol for mass spectral analysis. Samples were ionized by ESI with a Micromass LCT Premier TOF Mass Spectrometer. The LC was performed on an Acquity Ultra Performance BEH C18, $1.7 \mu \mathrm{m}, 2.1 \times 100 \mathrm{~mm}$ column on a gradient of $10-60 \%$ acetonitrile/water $0.1 \%$ formic acid over 20 minutes at a flow rate of $0.25 \mathrm{~mL} / \mathrm{min}$. The capillary and sample cone voltages were 2000 and $30 \mathrm{~V}$ respectively. The desolvation and source temperature were 350 and $100{ }^{\circ} \mathrm{C}$. The cone and desolvation gas flow rates were 20 and $700 \mathrm{~L} /$ hour. Analysis was performed with MassLynx 4.1. Accurate mass measurements were obtained in W-mode. The spectra were processed using the Mass Lynx 4.1 mass measure, in which the mass spectrum of peaks of interest was smoothed and centered with TOF mass correction, locking on the reference infusion of ajmalicine $(\mathrm{m} / \mathrm{z} 353.1865,1 \mathrm{nM}$ solution at $20 \mathrm{uL} / \mathrm{min})$ reference. All data from analog treated samples were compared to a negative control from a culture containing only tryptamine.

\section{E. Analogue Purification by Preparative HPLC and NMR analysis}

Alkaloid root extracts were purified on a $10 \times 20 \mathrm{~mm}$ Vydac reverse phase column using a gradient of 20$50 \%$ acetonitrile/ water $(0.1 \%$ TFA or $0.1 \%$ formic acid) over 30 minutes. The mixture was monitored at $254 \mathrm{~nm}$ and fractions containing the alkaloid analogues of interest were combined and concentrated. Isolated alkaloids were analyzed by NMR on a Bruker AVANCE-600 NMR spectrometer equipped with a $5 \mathrm{~mm}{ }_{1} \mathrm{H}\left\{{ }_{13} \mathrm{C}, 31 \mathrm{P}\right\}$ cryo-probe. 


\section{Tabulated ${ }^{1} \mathrm{H}-\mathrm{NMR}$ Data}

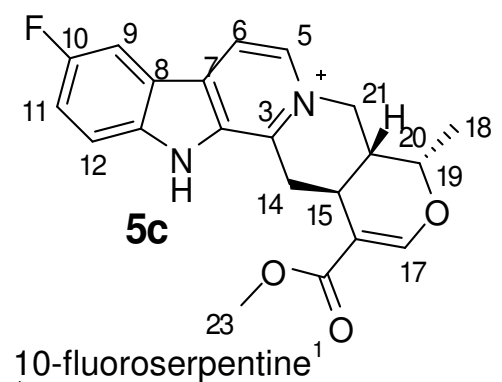

${ }^{1} \mathrm{HNMR}\left(\mathrm{CD}_{3} \mathrm{OD}\right) \_8.52(1 \mathrm{H}, \mathrm{d}, J 6.4, \mathrm{H}-6), 8.37(1 \mathrm{H}, \mathrm{d}, J 6.4, \mathrm{H}-5), 8.13(\mathrm{dd}, J 2.3,8.4), 7.79(1 \mathrm{H}, \mathrm{dd}, J$ 4.0, 9.0), $7.73(1 \mathrm{H}, \mathrm{d}, J 1.7, \mathrm{H}-17), 7.62(1 \mathrm{H}, \mathrm{td}, J 2.7,9.0), 4.90(1 \mathrm{H}, \mathrm{dd}, J 4.0,13.4, \mathrm{HB}-21), 4.78(1 \mathrm{H}$, dd, J 4.2, 6.7, H-19), 4.75 (1H, dd, J 5.0, 18.4, Ha-14), 4.67 (1H, t, J 13.5, Ha-21), 3.82 (3H, s, H-23), $3.23(1 \mathrm{H}, \mathrm{dd}, J 11.4,18.4, \mathrm{Hb}-14), 3.12(1 \mathrm{H}, \mathrm{tdd}, J 1.7,5.4,11.7, \mathrm{H}-15), 2.75(1 \mathrm{H}, \mathrm{tt}, J 4.0,12.4, \mathrm{H}-20)$, $1.36(3 \mathrm{H}, \mathrm{d}, \mathrm{J} 6.4, \mathrm{H}-18)$<smiles>COC(=O)C1=CO[C@H](C)[C@H](C)[C@H]1CC1=c2[nH]c3cc(F)ccc3c2=CC=[N+]1</smiles>

11-fluoroserpentine

${ }^{1} \mathrm{HNMR}\left(\mathrm{CD}_{3} \mathrm{OD}\right)$ _ $8.42(1 \mathrm{H}, \mathrm{d}, J 6.7, \mathrm{H}-6), 8.35(1 \mathrm{H}, \mathrm{dd}, J 5.4,3.7), 8.30$ (d, J 6.7, H-5), $7.79(1 \mathrm{H}, \mathrm{dd}, J$ 4.0, 9.0), $7.73(1 \mathrm{H}, \mathrm{d}, J 1.7, \mathrm{H}-17), 7.62(1 \mathrm{H}, \mathrm{td}, J 2.7,9.0), 4.84(1 \mathrm{H}, \mathrm{dd}, J 4.0,13.4), \mathrm{HB}-21), 4.71(1 \mathrm{H}$, dd, J 4.0, 6.7, H-19), 4.66 (1H, dd, J 5.0, 18.4, Ha-14), 4.58 (1H, t, J 12.7, Ha-21), 3.75 (3H, s, H-23), $3.15(1 \mathrm{H}, \mathrm{dd}, J 12.4,17.4, \mathrm{Hb}-14), 3.04(1 \mathrm{H}, \mathrm{tdd}, J 1.4,5.4,11.4, \mathrm{H}-15), 2.68(1 \mathrm{H}, \mathrm{tt}, J$ 4.4, 12.4, H-20), $1.29(3 \mathrm{H}, \mathrm{d}, \mathrm{J} 6.7, \mathrm{H}-18)$<smiles>COC(=O)C1=CO[C@@H](C)[C@H]2C[n+]3ccc4c([nH]c5c(C)cccc54)c3C[C@H]12</smiles>

12-methylserpentine

Many NMR peaks were masked by solvent and not tabulated.

${ }^{1} \mathrm{HNMR}\left(\mathrm{CD}_{3} \mathrm{OD}\right) \_8.35(1 \mathrm{H}, \mathrm{d}, J 6.7, \mathrm{H}-6), 8.20(1 \mathrm{H}, \mathrm{d}, J 6.4, \mathrm{H}-5), 8.06(\mathrm{~d}, J$ 8.0), $7.59(1 \mathrm{H}, \mathrm{d}, J 1.7, \mathrm{H}-$ 17), $7.45(1 \mathrm{H}, \mathrm{d}, J 7.4), 7.24(1 \mathrm{H}, \mathrm{dd}, J 7.4,8.0), 4.53(1 \mathrm{H}, \mathrm{t}, J 13.4, \mathrm{Ha}-21), 3.68(3 \mathrm{H}, \mathrm{s}, \mathrm{H}-23), 2.73(3 \mathrm{H}$, s), $1.21(3 \mathrm{H}, \mathrm{d}, J 6.7, \mathrm{H}-18)$.

\footnotetext{
${ }^{1}$ Analysis of coupling constants for protons $\mathrm{H} 21, \mathrm{H} 20, \mathrm{H} 19$ and $\mathrm{H} 15$, confirmed the assignment of these analogs as derivatives with the stereochemistry of 5 .
} 
<smiles>COC(=O)C1=CO[C@@H](C)[C@H]2C[C@H]3c4[nH]c5ccc(F)cc5c4CCN3C[C@H]12</smiles>

10-fluoroajmalicine

Characteristic ${ }_{1} \mathrm{H}-\mathrm{NMR}$ shifts and coupling constants were consistent with ajmalicine. ${ }^{2}$

$\left.{ }^{1} \mathrm{HNMR}_{(\mathrm{CD}} \mathrm{OD}\right){ }_{2} 7.61(1 \mathrm{H}, \mathrm{d}, J 2.0), 7.36(1 \mathrm{H}, \mathrm{dd}, J 4.50,8.7), 7.19(1 \mathrm{H}, \mathrm{dd}, J 2.3,9.4), 6.96(1 \mathrm{H}, \mathrm{td}, J$ 2.3, 9.4), $4.59(1 \mathrm{H}, \mathrm{qd}, J 3.7,6.7), 3.76(3 \mathrm{H}, \mathrm{s}), 3.69(1 \mathrm{H}, \mathrm{br} \mathrm{d}, J 12.0), 3.12(1 \mathrm{H}, \mathrm{dd}, J 4.7,17.0), 2.83$ $(1 \mathrm{H}$, br t,$J 11.0), 2.25(1 \mathrm{H}, \mathrm{m}), 1.26(3 \mathrm{H}, \mathrm{d}, J 6.7)$.<smiles>CC=C1CN2CSC[C@]23C(=C1C(=O)OC)Nc1c(C)cccc13</smiles>

12-methylakuammicine ${ }^{1} \mathrm{HNMR}\left(\mathrm{CD}_{3} \mathrm{OD}\right)$ _ $7.16(1 \mathrm{H}, \mathrm{d}, J$ 7.3), $6.98(1 \mathrm{H}, \mathrm{d}, J 7.9), 6.82(1 \mathrm{H}, \mathrm{dd}, J 7.9,7.3), 5.69(1 \mathrm{H}, \mathrm{q}, J 6.7 \mathrm{H}-$ 17), $4.48(1 \mathrm{H}$, bs $\overline{\mathrm{H}}-3$ ), $4.21(1 \mathrm{H}, \mathrm{bd}, \mathrm{J} 14.6, \mathrm{H}-21 \mathrm{a}), 4.02(1 \mathrm{H}, \mathrm{bs}, \mathrm{H} 15 \mathrm{a}), 3.72(3 \mathrm{H}, \mathrm{s} \mathrm{H}-23), 3.70(1 \mathrm{H}, \mathrm{m}$, $\mathrm{H}-6 \mathrm{a}), 3.63(1 \mathrm{H}, \mathrm{d}, J 14.6 \mathrm{H}-21 \mathrm{~b}), 3.52(1 \mathrm{H}, \mathrm{dd}, J 6.7,12.2 \mathrm{H}-5 \mathrm{a}), 2.68(1 \mathrm{H}, \mathrm{td}, J 6.7,13.4 \mathrm{H}-5 \mathrm{~b}), 2.48(1 \mathrm{H}$, $\mathrm{dt}, 2.4,14.6, \mathrm{H}-14 \mathrm{~S}), 2.16\left(3 \mathrm{H}, \mathrm{s}, \mathrm{Ar}-\mathrm{CH}_{3}\right), 2.02(1 \mathrm{H}, \mathrm{dd}, J$ 6,7, 14.0, H-6b), $1.6(3 \mathrm{H}, \mathrm{d}, J$ 7.3, H-18), 1.44 $(1 \mathrm{H}, \mathrm{dt}, \mathrm{J} 2.4,14.6, \mathrm{H}-14 \mathrm{R})$.<smiles>C/C=C1\CN2CC[C@]34c5ccc(F)cc5NC(=C1C(=O)OCc1ccccc1)[C@H]3[C@H]24</smiles>

11-fluoroakuammcine ${ }^{1} \mathrm{HNMR}\left(\mathrm{CD}_{3} \mathrm{OD}\right) \_7.41(1 \mathrm{H}, \mathrm{dd}, J 5.4,8.4), 6.8(1 \mathrm{H}, \mathrm{dd}, J 2.0,9.4), 6.69(1 \mathrm{H}, \mathrm{td}, J 1.7,9.4), 5.79(1 \mathrm{H}, \mathrm{q}$, J 7.0, H-17), $4.59(1 \mathrm{H}, \mathrm{s}, \mathrm{H}-3), 4.34(1 \mathrm{H}, \mathrm{d}, J 13.7, \mathrm{H}-21 \mathrm{a}), 4.17(1 \mathrm{H}, \mathrm{s}, \mathrm{H}-15 \mathrm{a}), 3.85(3 \mathrm{H}, \mathrm{s}, \mathrm{H}-23), 3.75$ $(1 \mathrm{H}, \mathrm{d}, J 13.7, \mathrm{H}-6 \mathrm{a}), 3.67(1 \mathrm{H}, \mathrm{dd}, J 7.7,12.7, \mathrm{H}-21 \mathrm{~b}), 3.52(1 \mathrm{H}, \mathrm{dd}, J 6.4,10.7, \mathrm{H}-5 \mathrm{a}), 2.78(1 \mathrm{H}, \mathrm{td}, J$, 6.7, 13.7, H-5b), 2.61 (1H, br d, J 14.4, H-14S), 2.15 (1H, dd, J 14.0, 7.0, H-6b) 1.7 (3H, d, J 7.0, H-18), $1.55(1 \mathrm{H}$, br d, J 15.1, H-14R).

\footnotetext{
${ }^{2}$ A. Phillipson, J. D.; Supavita, N., Alkaloids from Uncaria Species .8. Alkaloids of Uncaria-Elliptica. Phytochemistry 1983, 22, (8), 1809-1813. B. Lounasmaa, M.; Kan, S. K., A 400 Mhz H-1-Nmr Study of the 8 Basic Heteroyohimbine Alkaloids. Tetrahedron 1980, 36, (11), 1607-1611.
} 


\section{1 - 10-fluoroserpentine, 5c}
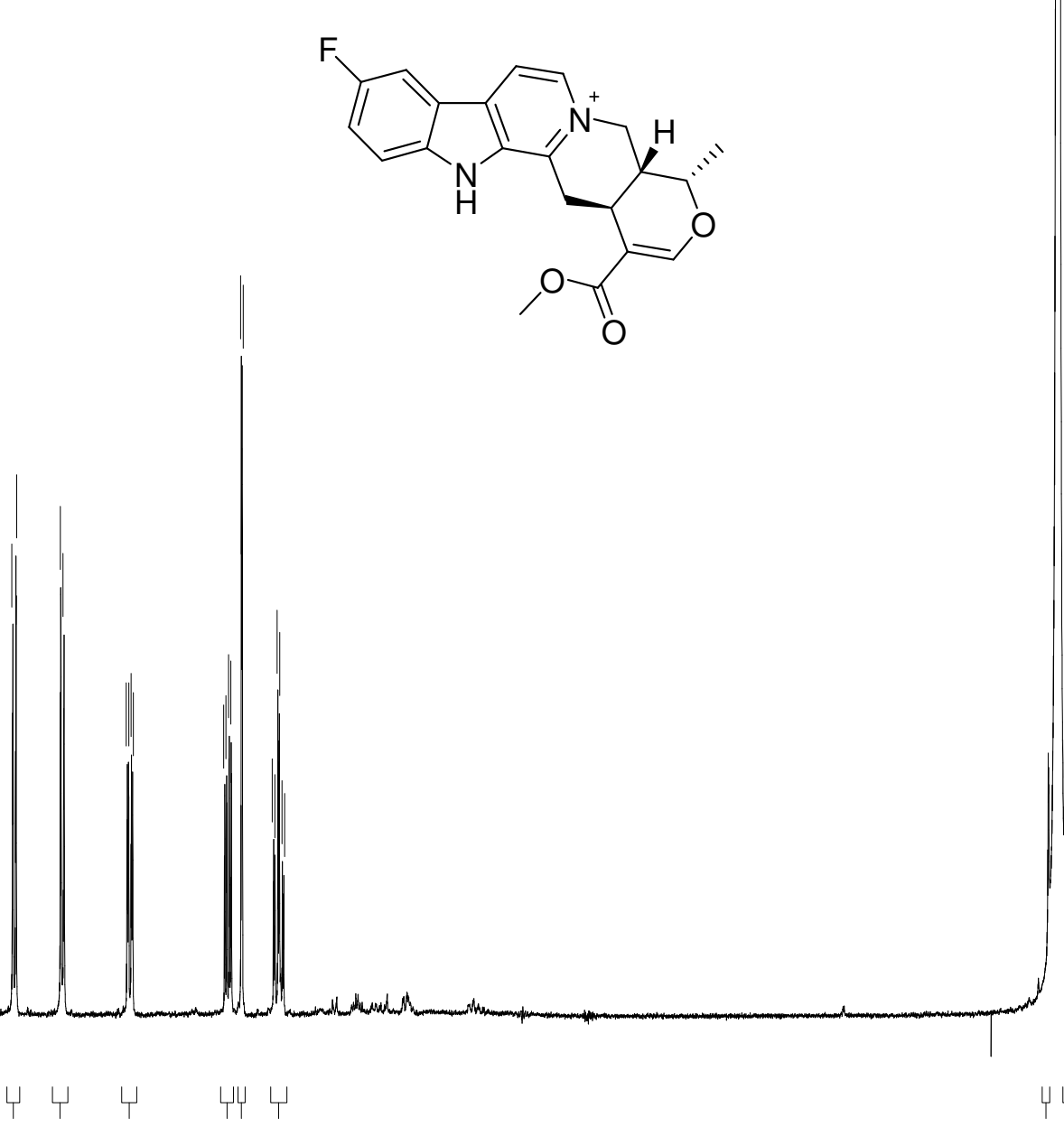

$\begin{array}{lll}1.01 .0 & 1.0 & 10091.1\end{array}$

$\biguplus \uparrow$

0.8.401911.1

2.8

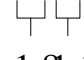

1.1

3.0

4.0

3.5




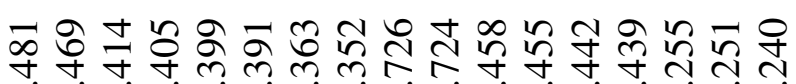

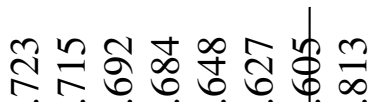

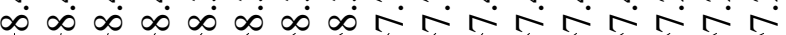

3.2 - 11-fluoroserpentine, $5 d$

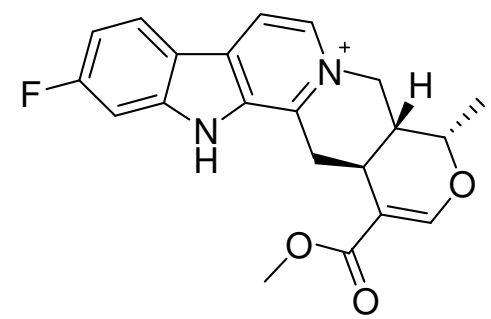

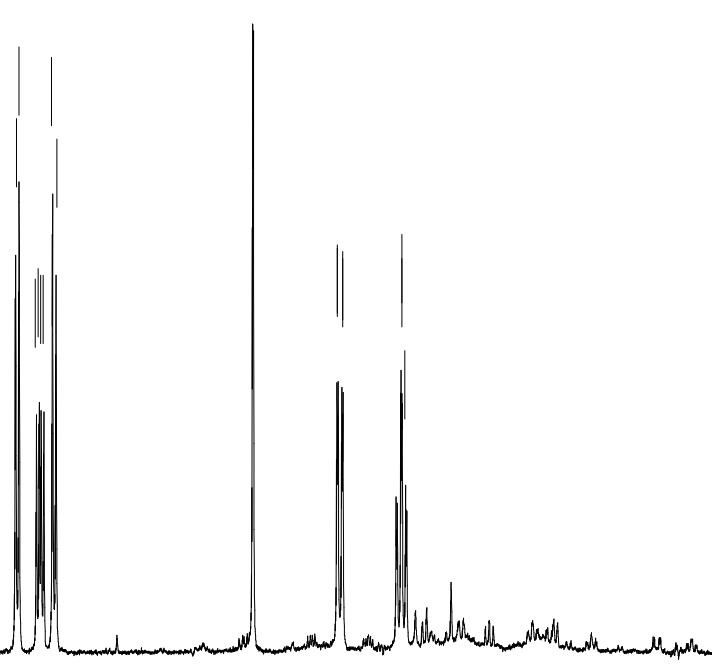
Whan

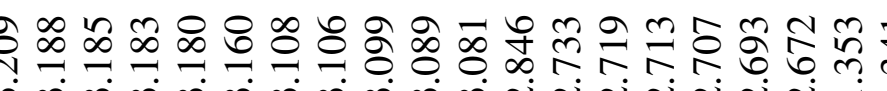

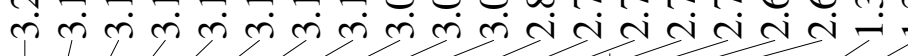

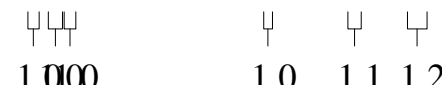

† प प५

1.62144 .3

3.2

2.5.3 1.2

3.2 


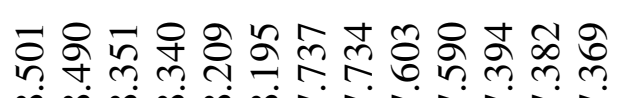

3.3 - 12-methylserpentine, 5e<smiles></smiles>

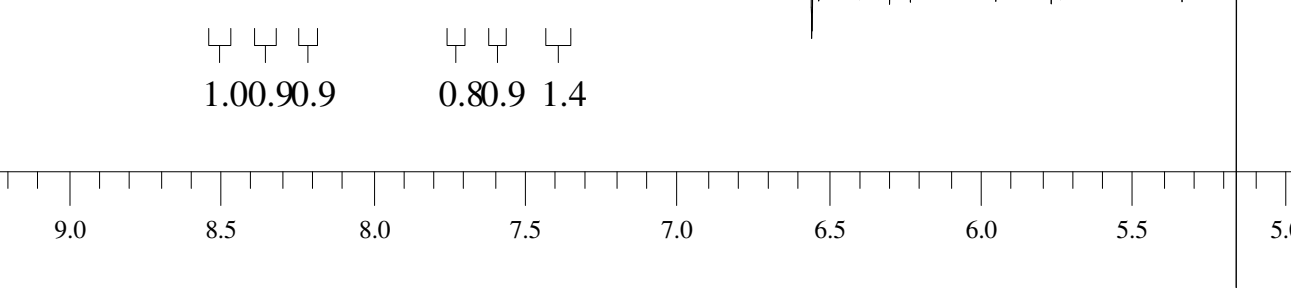




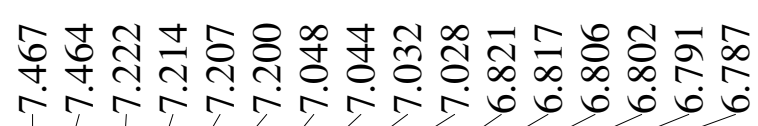

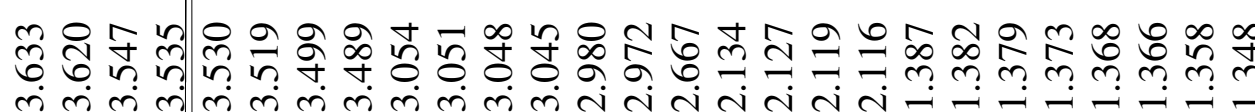

3.4 - 10-fluoroajmalicine, 4c
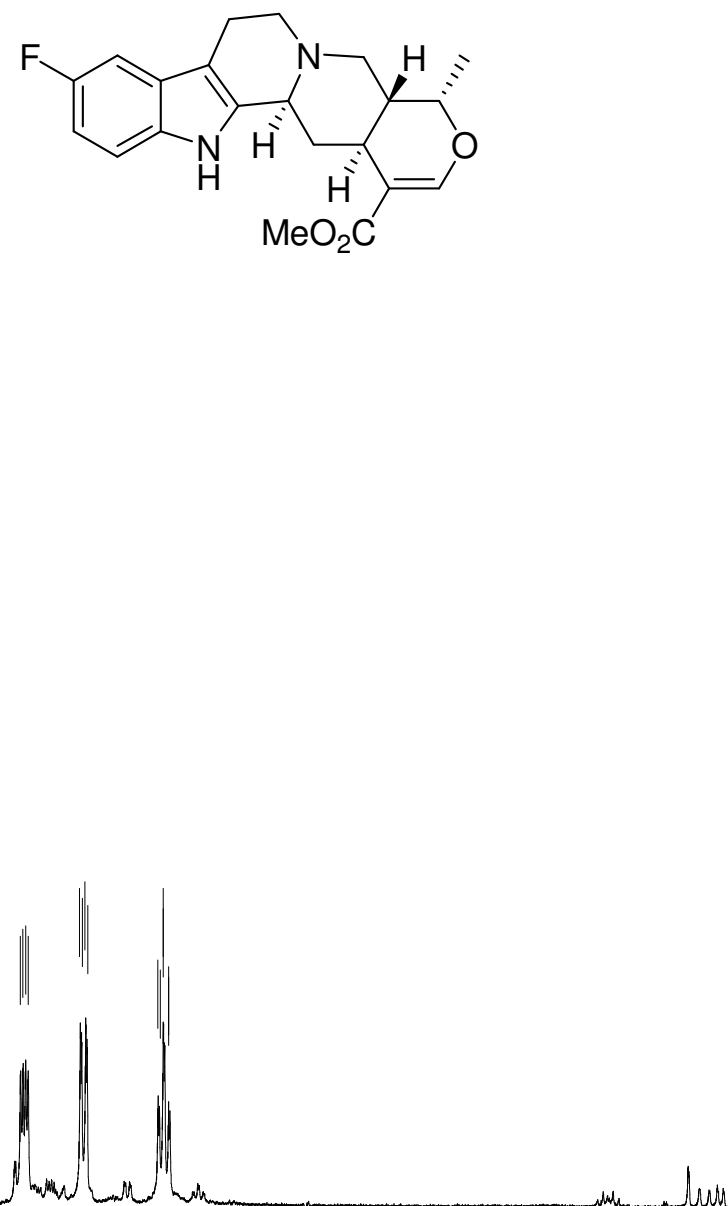

$५ \quad ५ \quad ५ \quad ५$

1.1

3.72. 4

$1.61 .4 \quad 1.1$

1.0

$\begin{array}{ll}1.3 & 2.7\end{array}$ 
3.5 - 12-methylakuammicine, $8 \mathrm{e}$
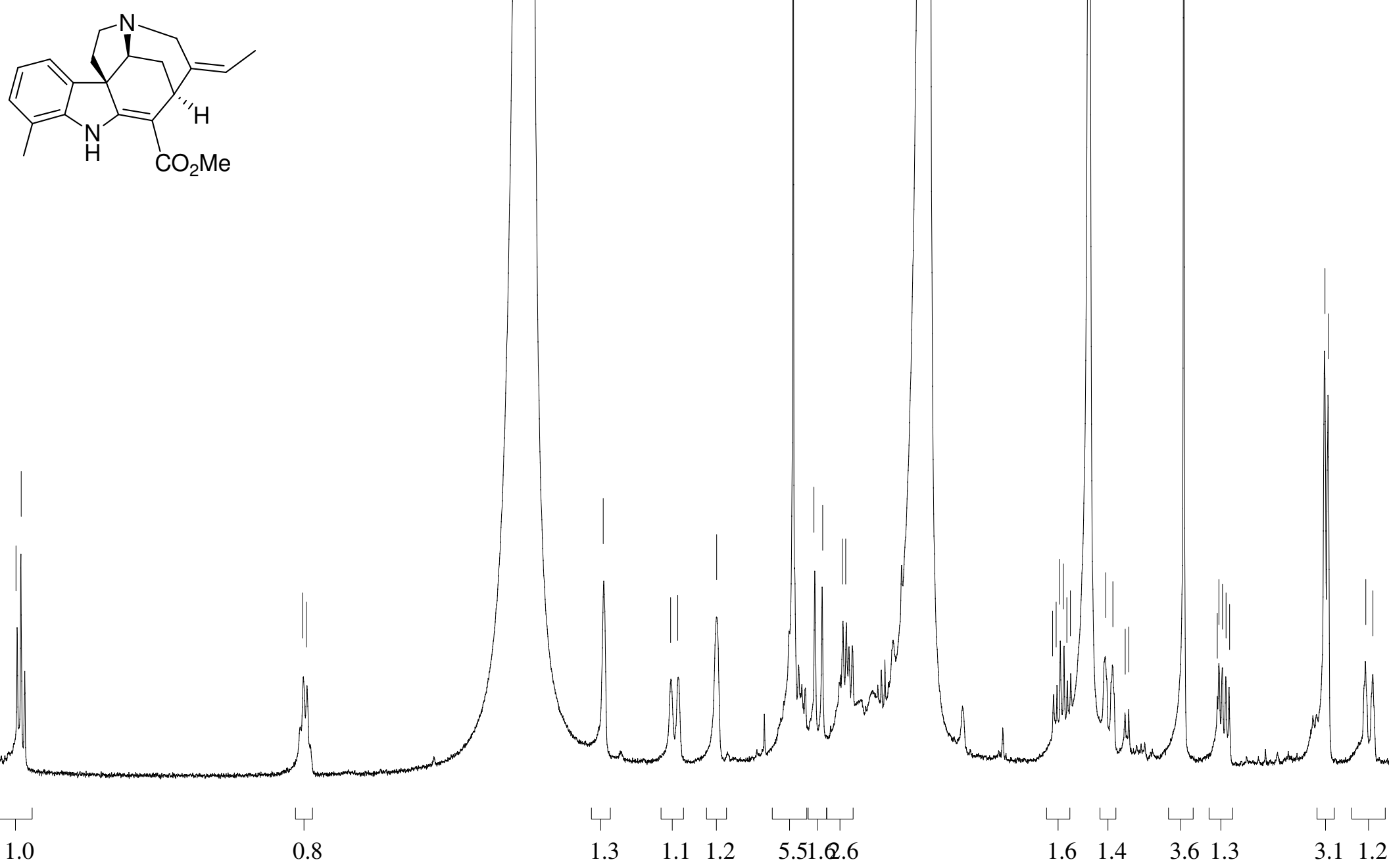


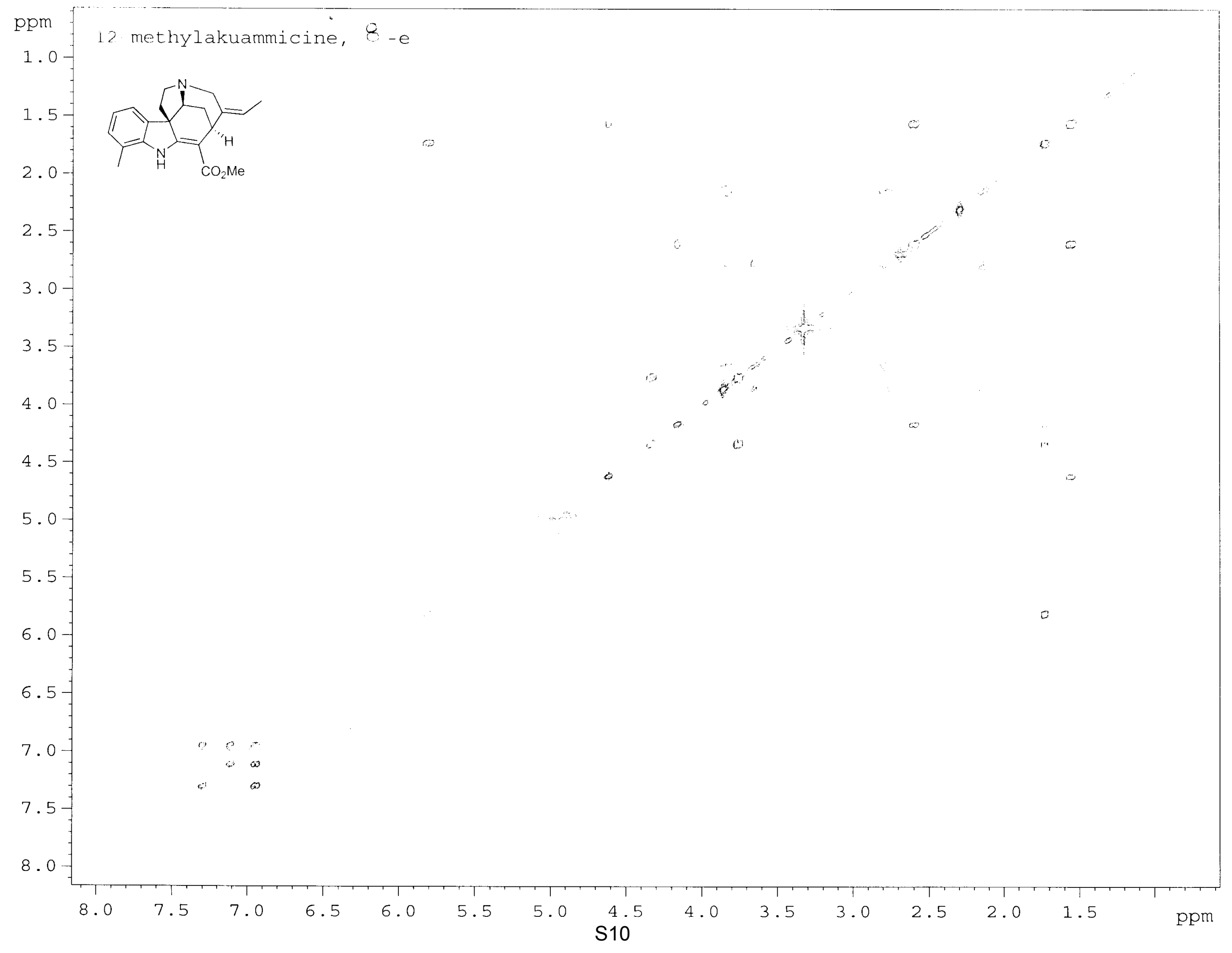


3.7 - 11-fluoroakuammicine, 8d
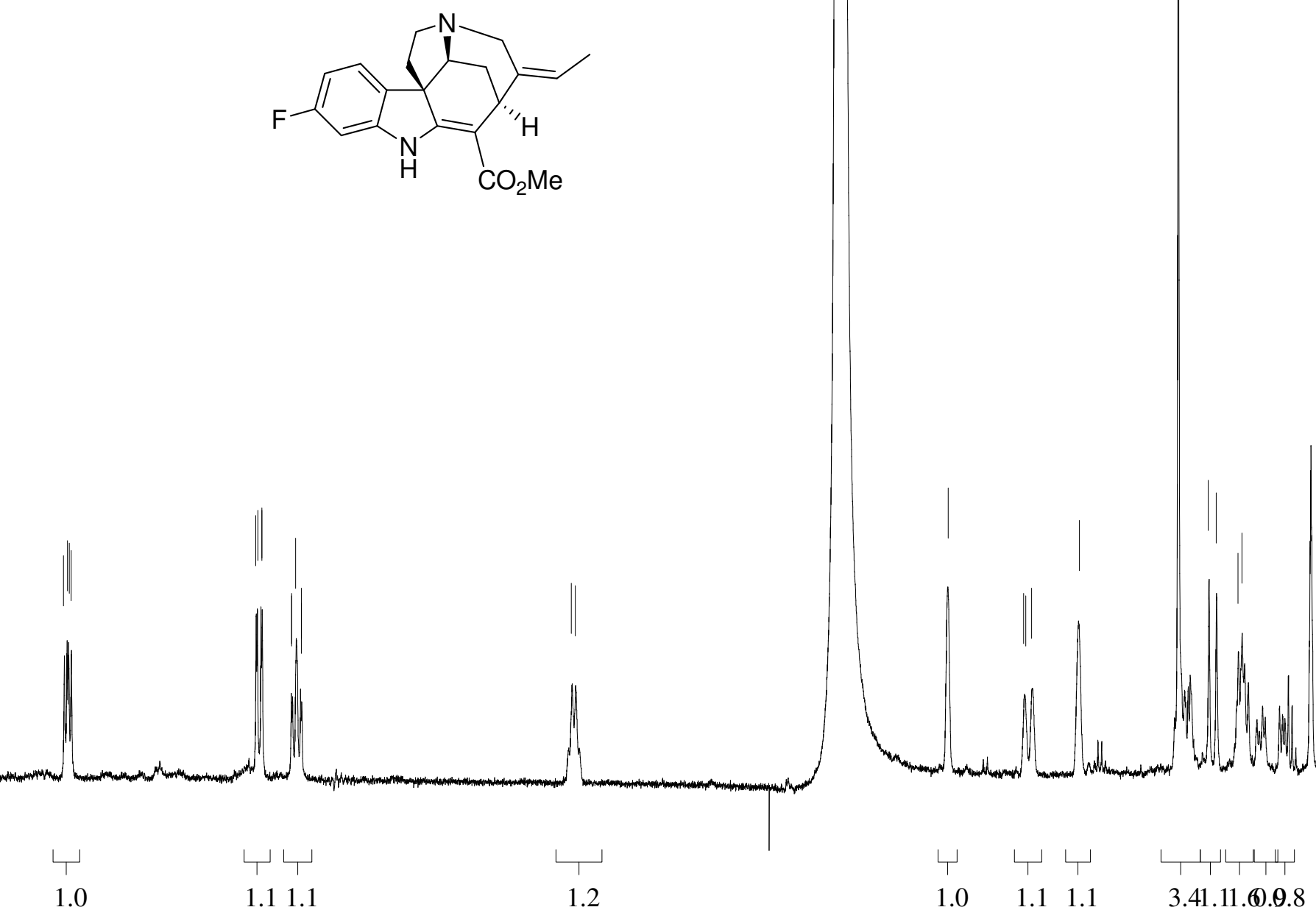


\begin{tabular}{|c|c|c|c|c|c|c|}
\hline \multirow[b]{2}{*}{ Structure } & & \multicolumn{5}{|c|}{ Tryptamine Analog } \\
\hline & & $\mathbf{a}$ & c & d & e & $\mathbf{f}$ \\
\hline & Serpentine & 5 & $5-c$ & $5-d$ & $5-e$ & $5-f$ \\
\hline & Expected $[\mathrm{M}+\mathrm{H}]$ & 349.1552 & 367.1458 & 367.1458 & 363.1709 & 365.1501 \\
\hline & Observed $[\mathrm{M}+\mathrm{H}]$ & 349.1553 & 367.1476 & 367.1450 & 363.1702 & 365.1515 \\
\hline & accuracy (ppm) & 0.3 & 4.9 & -2.2 & -1.9 & 3.8 \\
\hline & RT (minutes) & 8.44 & 8.83 & 8.98 & 10.24 & 6.99 \\
\hline & & hrc, s & hrc, s & hrc, s & hrc, s & hrc, s \\
\hline & Ajmalicine & 4 & $4-c$ & $4-d$ & $4-e$ & $4-f$ \\
\hline & Expected $[\mathrm{M}+\mathrm{H}]$ & 353.1865 & 371.1770 & 371.1770 & 367.2022 & 369.1814 \\
\hline & Observed $[\mathrm{M}+\mathrm{H}]$ & 353.1865 & 371.1776 & 371.1757 & 367.2011 & 369.1811 \\
\hline & accuracy (ppm) & 0.0 & 1.6 & -3.5 & -3.0 & -0.8 \\
\hline & $\mathrm{RT}$ (minutes) & 8.18 & 8.84 & 8.97 & 9.85 & 6.37 \\
\hline & & hrc, s & hrc, s & hrc, s & hrc, s & hrc, s \\
\hline & yohimbine & 6 & & & & \\
\hline & Expected $[\mathrm{M}+\mathrm{H}]$ & 355.2022 & 373.1927 & 373.1927 & 369.2179 & 371.1971 \\
\hline & Observed $[\mathrm{M}+\mathrm{H}]$ & 355.2010 & 373.1939 & 373.1927 & 369.2177 & 371.1956 \\
\hline & accuracy (ppm) & -3.4 & 3.2 & 0.0 & -0.5 & -4.0 \\
\hline & $\mathrm{RT}$ (minutes) & 6.30 & 6.86 & 7.55 & 8.04 & 3.40 \\
\hline & & hrc, s & hrc, s & hrc, s & hrc, s & hrc, s \\
\hline & vindoline & 2 & $2-c^{* \star}$ & & & \\
\hline & Expected $[\mathrm{M}+\mathrm{H}]$ & 457.2339 & 475.2244 & & & \\
\hline & Observed $[\mathrm{M}+\mathrm{H}]$ & 457.2357 & 475.2239 & & & \\
\hline & accuracy (ppm) & 3.9 & -1.1 & & & \\
\hline & $\mathrm{RT}$ (minutes) & 10.43 & 10.62 & & & \\
\hline & & $\mathrm{s}$ & $\mathrm{s}$ & & & \\
\hline & Catharanthine & 3 & $3-c^{*}$ & $3-d^{*}$ & $3-e^{*}$ & \\
\hline & Expected $[\mathrm{M}+\mathrm{H}]$ & 337.1916 & 355.1822 & 355.1822 & 351.2073 & \\
\hline & Observed $[\mathrm{M}+\mathrm{H}]$ & 337.1901 & 355.1823 & 355.1808 & 351.2070 & \\
\hline & accuracy (ppm) & -4.4 & 0.3 & -3.9 & -0.9 & \\
\hline & $\mathrm{RT}$ (minutes) & 8.67 & 9.08 & 9.12 & 9.53 & \\
\hline & & $\mathrm{s}$ & $\mathrm{s}$ & s & $s$ & \\
\hline & Tabersonine $^{\star \star}$ & $9^{*}$ & $9-c^{*}$ & $9-d^{*}$ & $9-e^{*}$ & \\
\hline & Expected $[\mathrm{M}+\mathrm{H}]$ & 337.1916 & 355.1822 & 355.1822 & 351.2073 & \\
\hline & Observed $[\mathrm{M}+\mathrm{H}]$ & 337.1903 & 355.1805 & 355.1815 & 351.2070 & \\
\hline & accuracy (ppm) & -3.9 & -4.8 & -2.0 & -0.9 & \\
\hline & RT (minutes) & 8.91 & 9.82 & 9.91 & 10.62 & \\
\hline & & $\mathrm{s}$ & s & s & $\mathrm{s}$ & \\
\hline & Vindolidine & $10^{\star *}$ & $10-c^{\star \star}$ & $10-d^{* *}$ & & \\
\hline & Expected $[\mathrm{M}+\mathrm{H}]$ & 427.2233 & 445.2138 & 445.2138 & & \\
\hline & Observed $[\mathrm{M}+\mathrm{H}]$ & 427.2234 & 445.2133 & 445.2144 & & \\
\hline & accuracy (ppm) & 0.2 & -1.1 & 1.3 & & \\
\hline & $\mathrm{RT}$ (minutes) & 9.92 & 10.43 & 10.54 & & \\
\hline & & $\mathrm{s}$ & $\mathrm{s}$ & $s$ & & \\
\hline & Akuammicine & 8 & 8-c & $8-d$ & $8-e$ & \\
\hline & Expected $[\mathrm{M}+\mathrm{H}]$ & 323.1760 & 341.1665 & 341.1665 & 337.1917 & \\
\hline & Observed $[\mathrm{M}+\mathrm{H}]$ & 323.1774 & 341.1663 & 341.1661 & 337.1903 & \\
\hline & accuracy (ppm) & 4.3 & -0.6 & -1.2 & -4.2 & \\
\hline H & $\mathrm{RT}$ (minutes) & 8.14 & 8.79 & 8.86 & 10.52 & \\
\hline & & hrc, s & hrc, s & hrc,s & hrc,s & \\
\hline
\end{tabular}

$\mathrm{RT}=$ retention time, hrc = hairy root culture, $\mathrm{s}=$ seedling

* Assignment based on exact mass and alkaloids previously characterized in $C$. roseus seedlings

** Assignment based on exact mass, fragmentation, and retention time. 


\section{1-5-fluorotryptamine hairy root extract, serpentine}

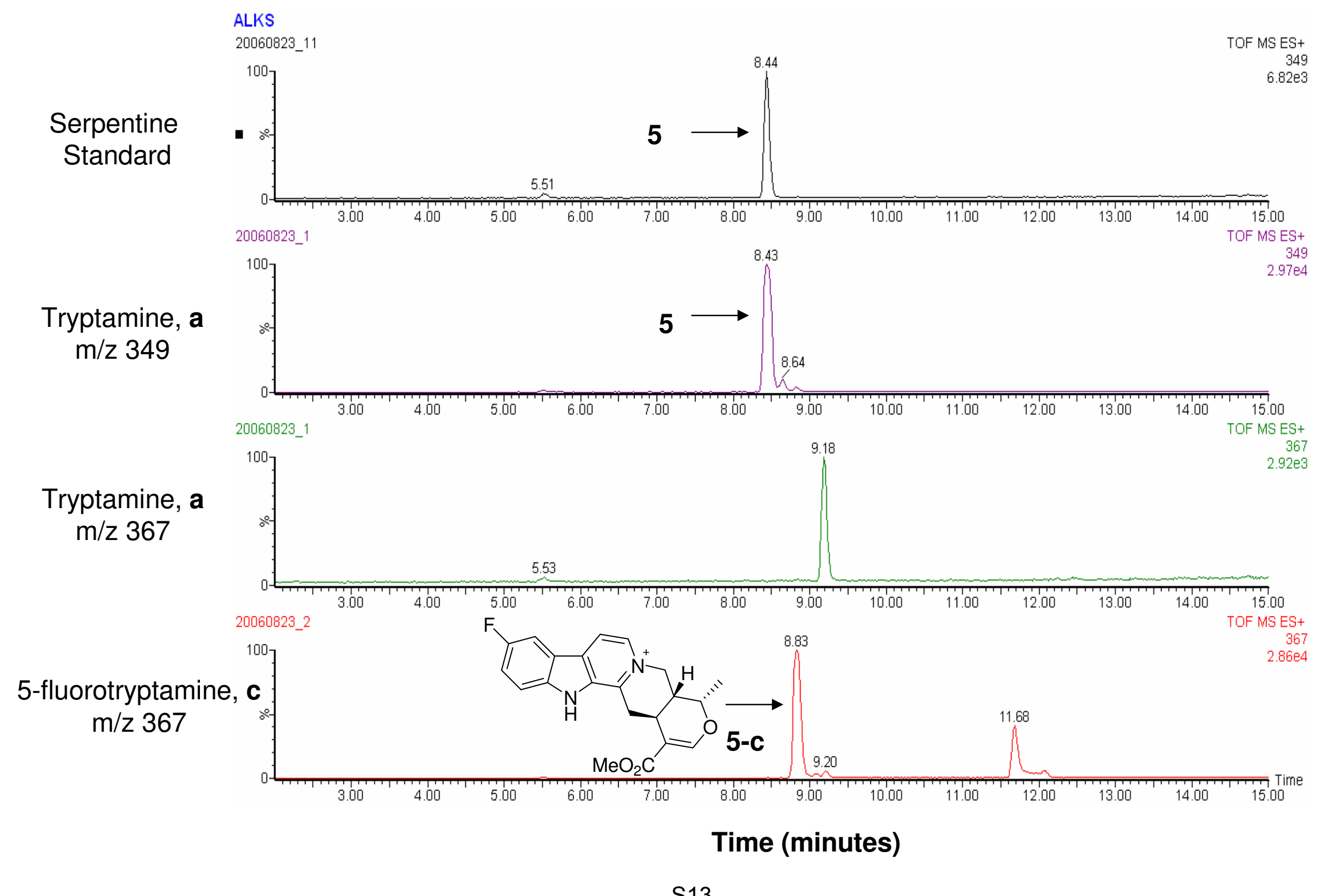




\section{2- 5-fluorotryptamine hairy root extract, ajmalicine}

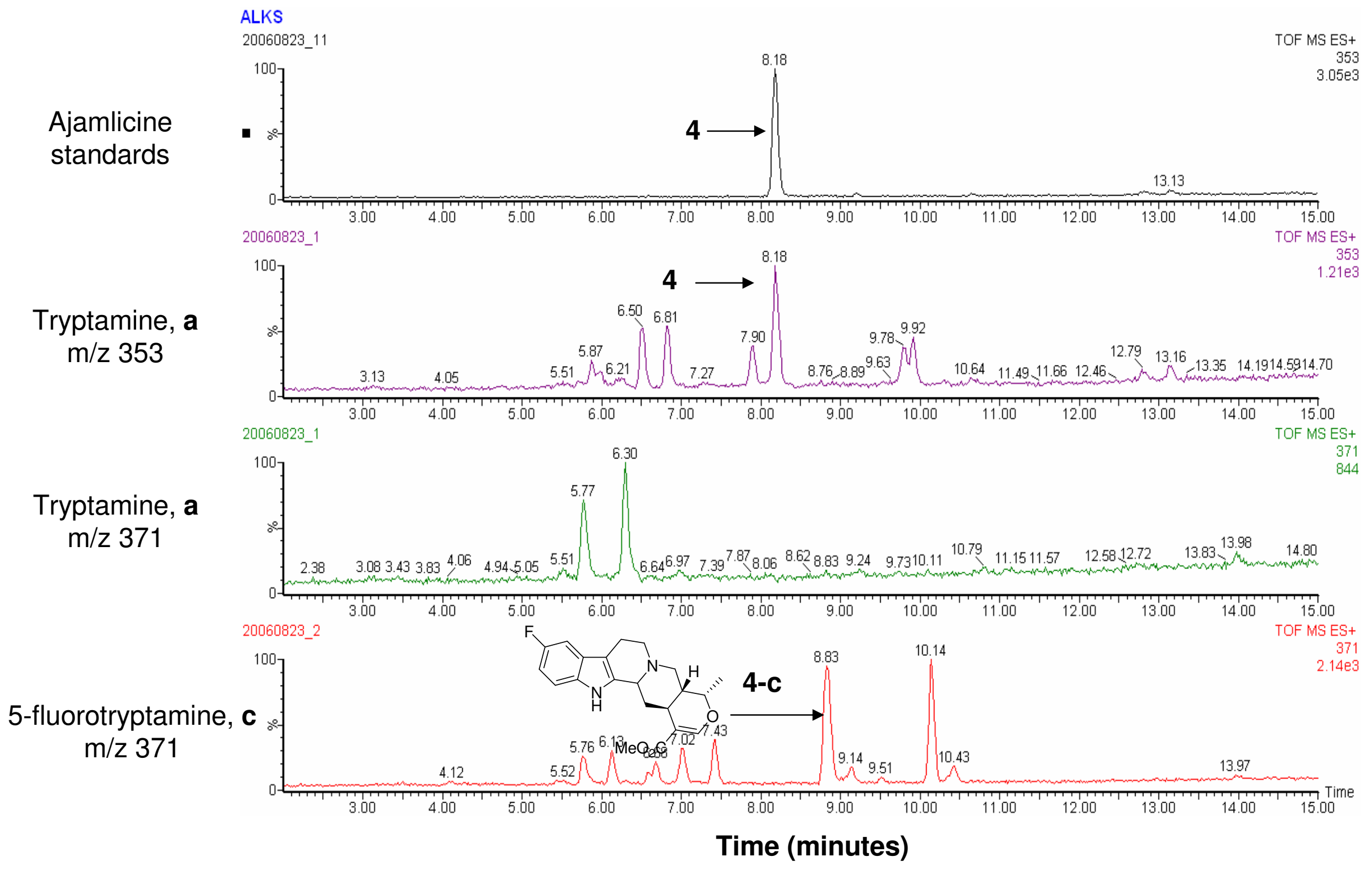




\section{3-5-fluorotryptamine hairy root extract, yohimbine}

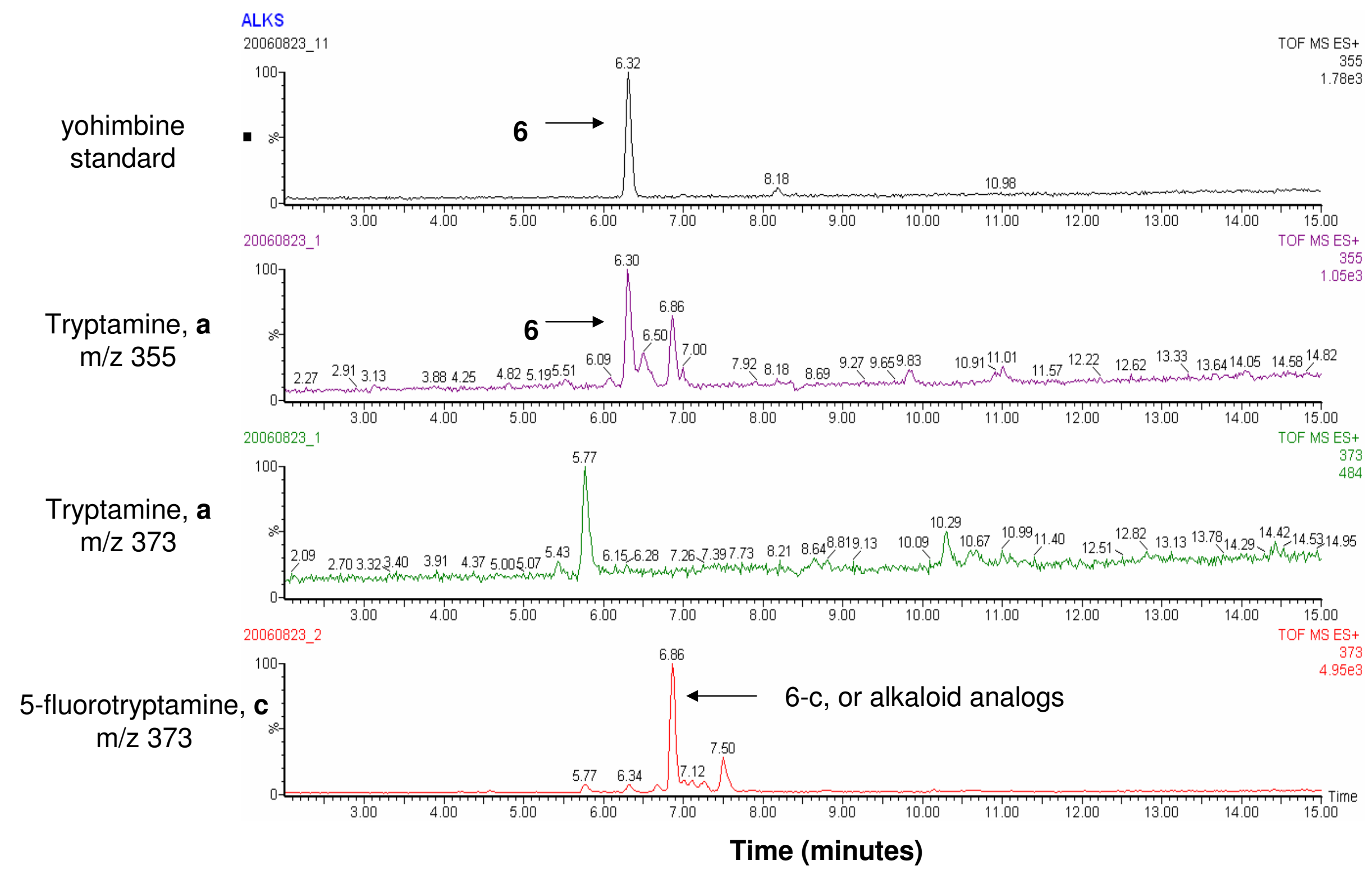




\section{4- 6-fluorotryptamine hairy root extract, serpentine}

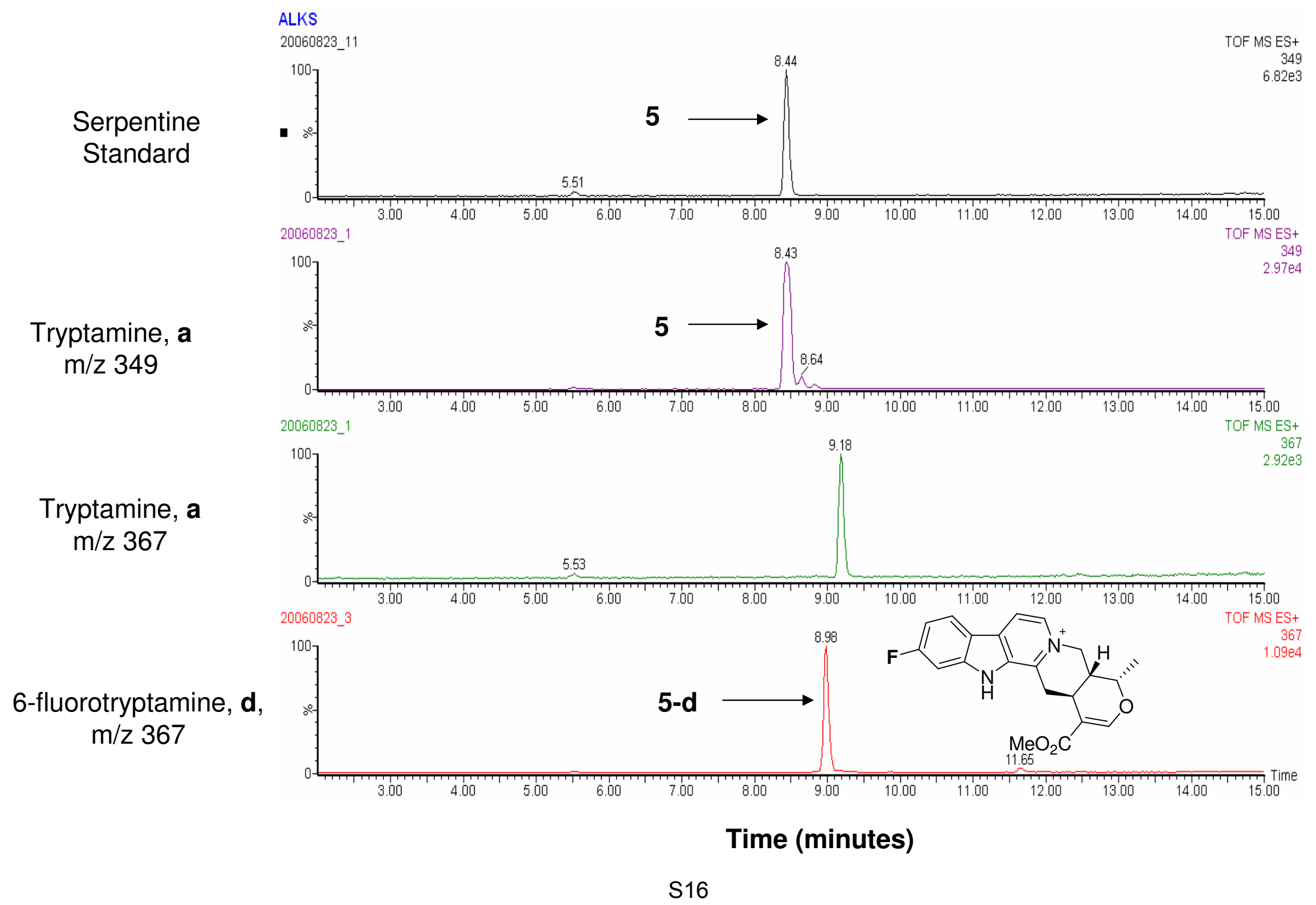




\section{5- 6-fluorotryptamine hairy root extract, ajmalicine}

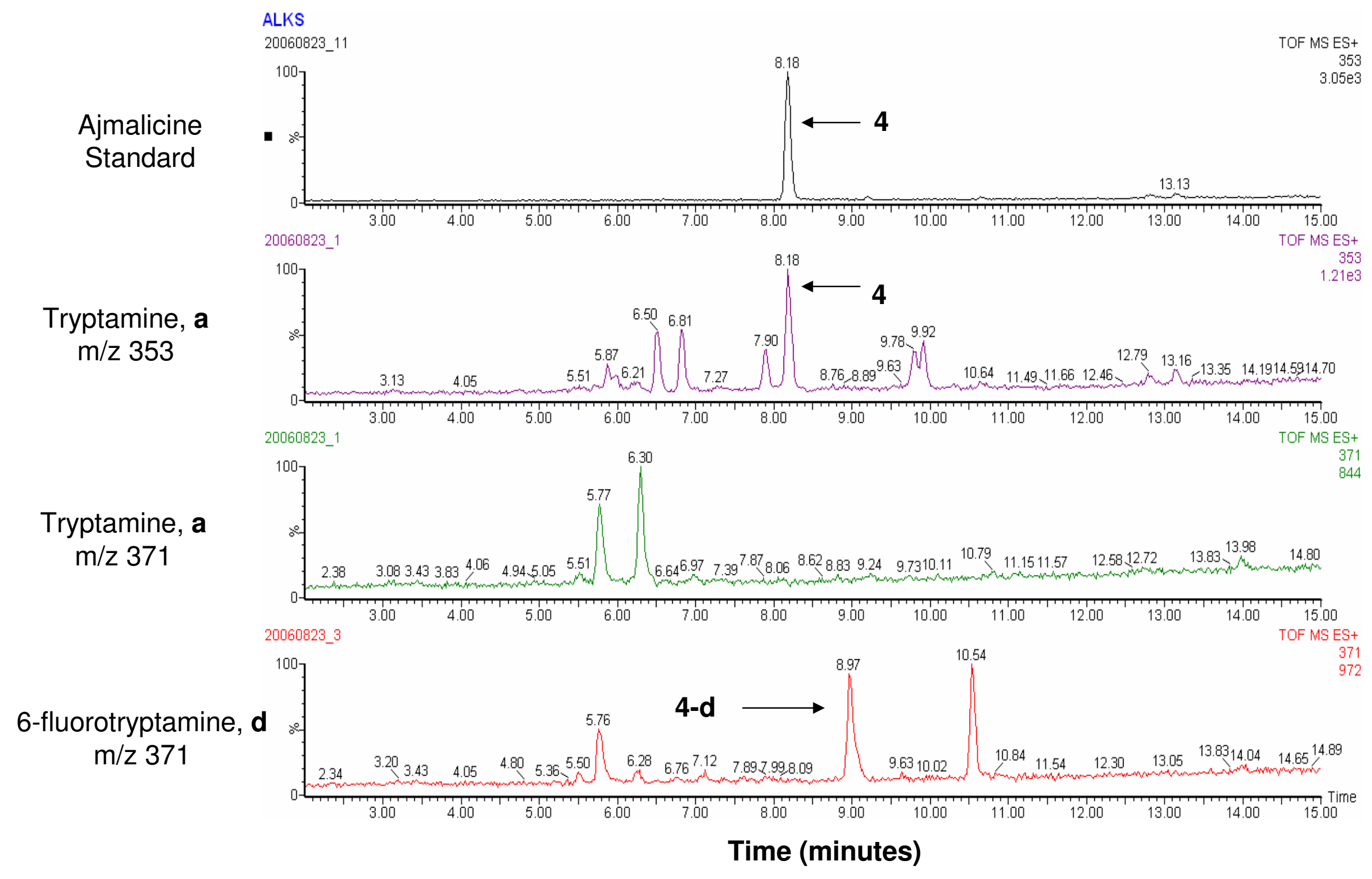




\section{6- 6-fluorotryptamine hairy root extract, yohimbine}

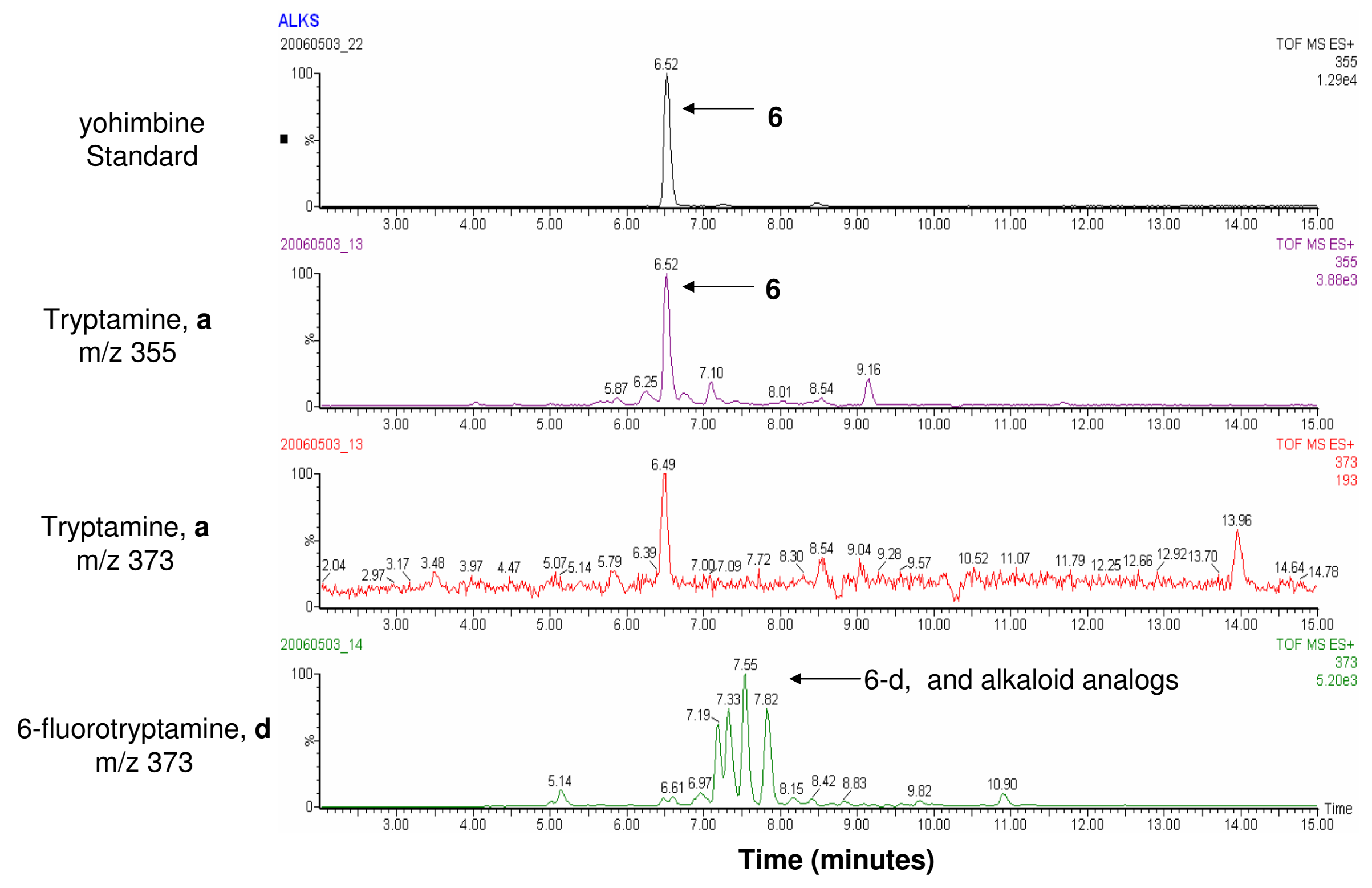




\section{7- 6-fluorotryptamine hairy root extract, akuammicine}

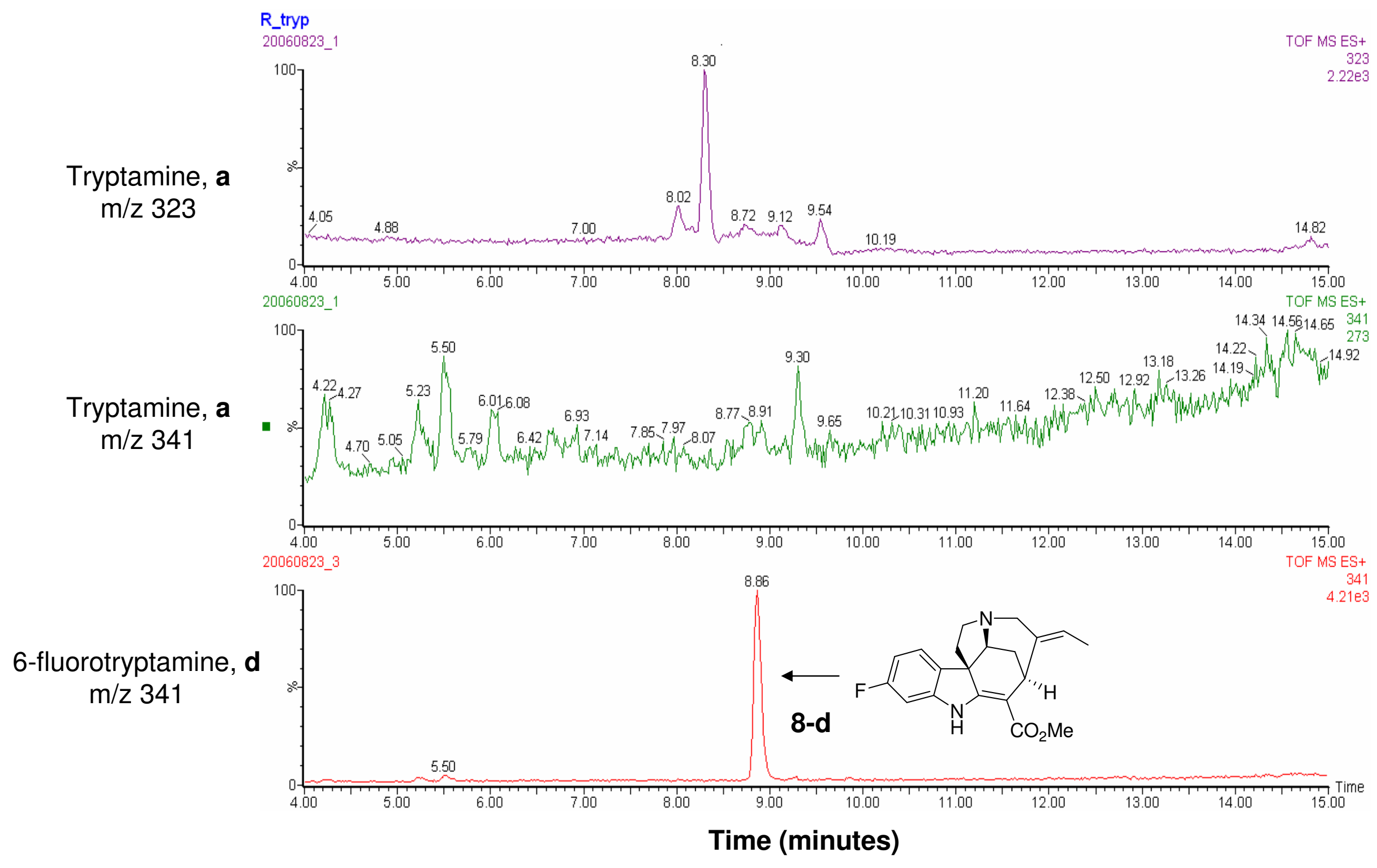




\section{8- 7-methyltryptamine hairy root extract, serpentine}

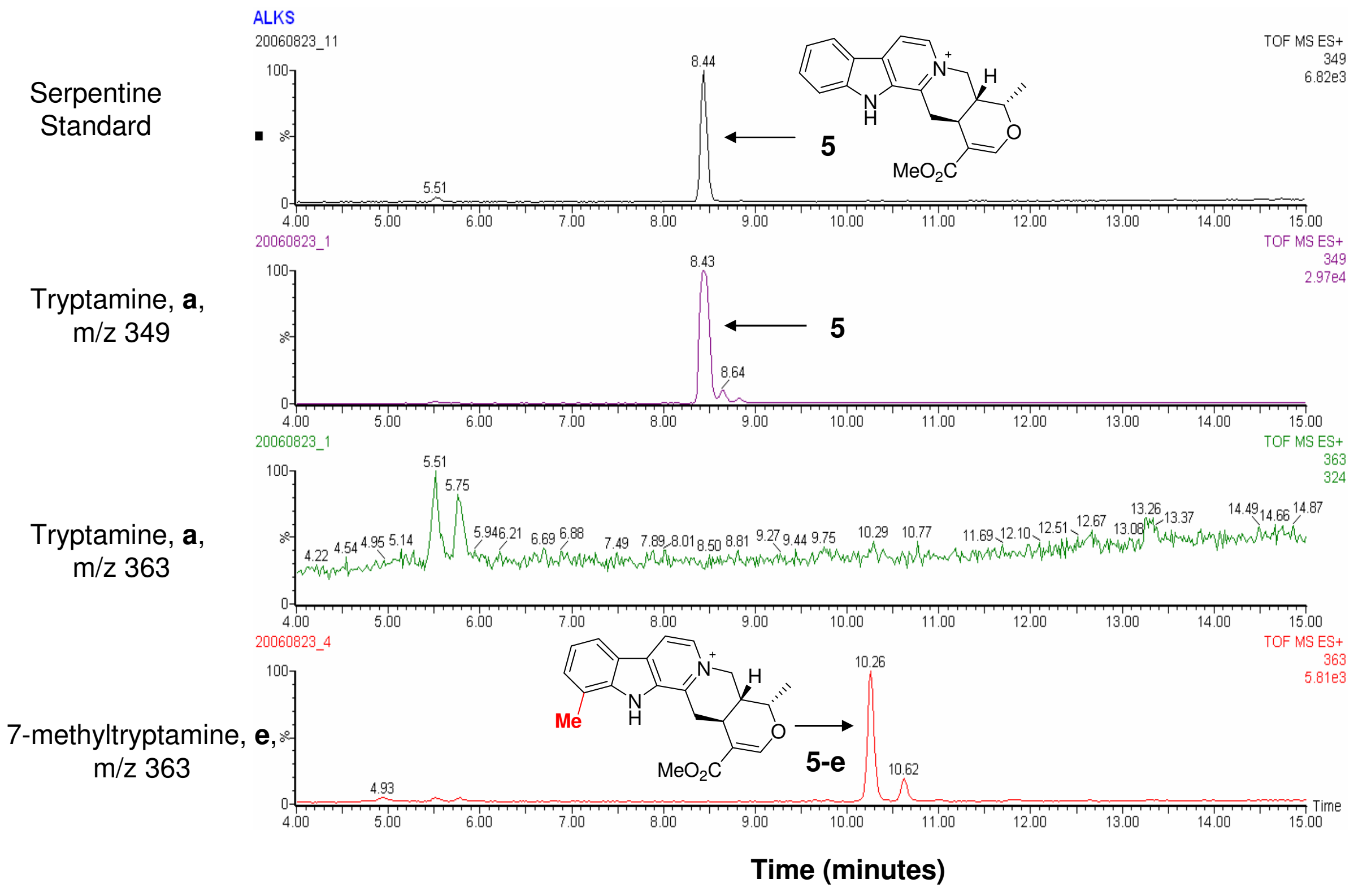




\section{9- 7-methyltryptamine hairy root extract, ajmalicine}

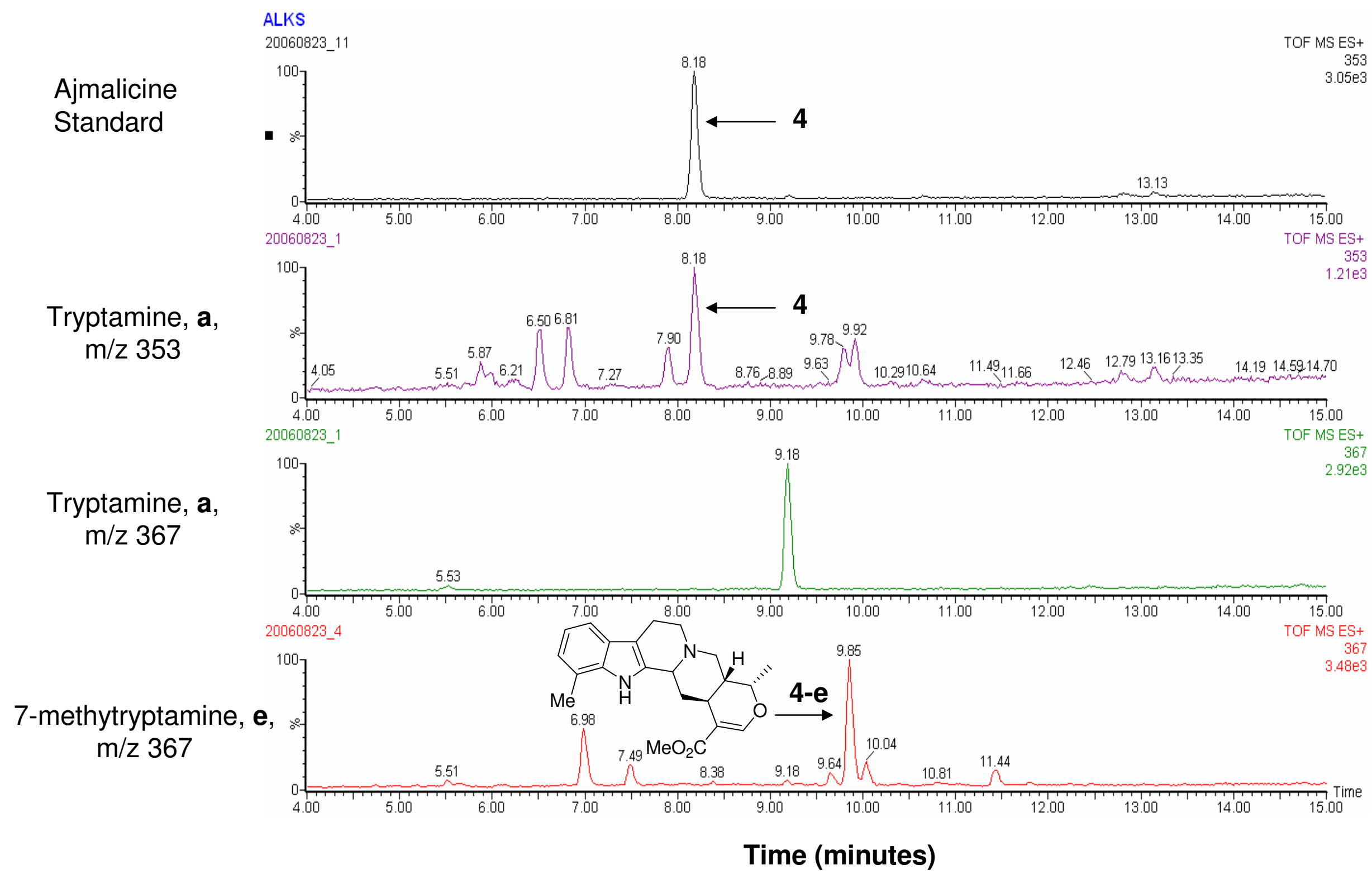




\subsection{0- 7-methyltryptamine hairy root extract, yohimbine}

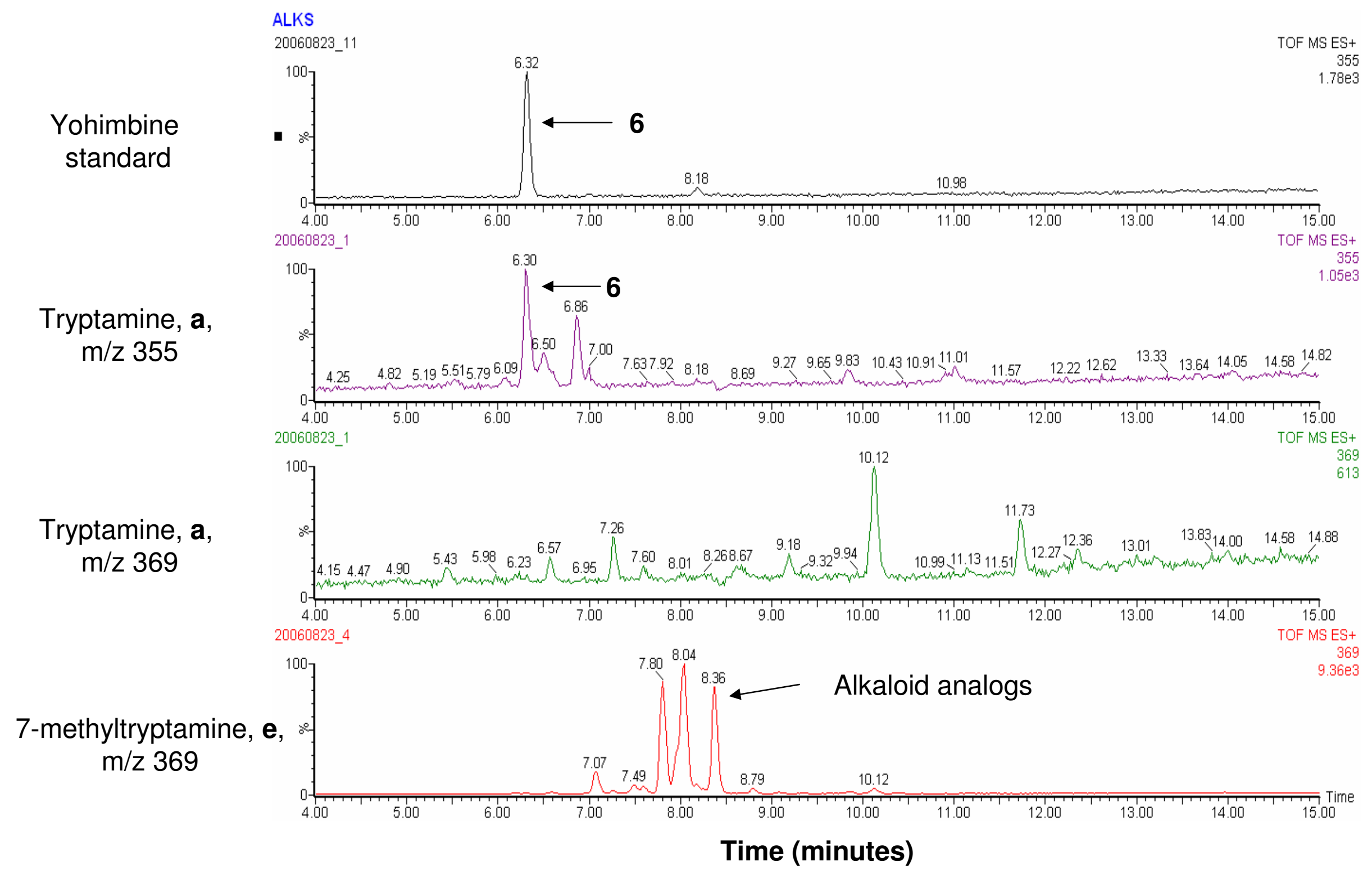




\subsection{1- 7-methyltryptamine hairy root extract, akuammicine}

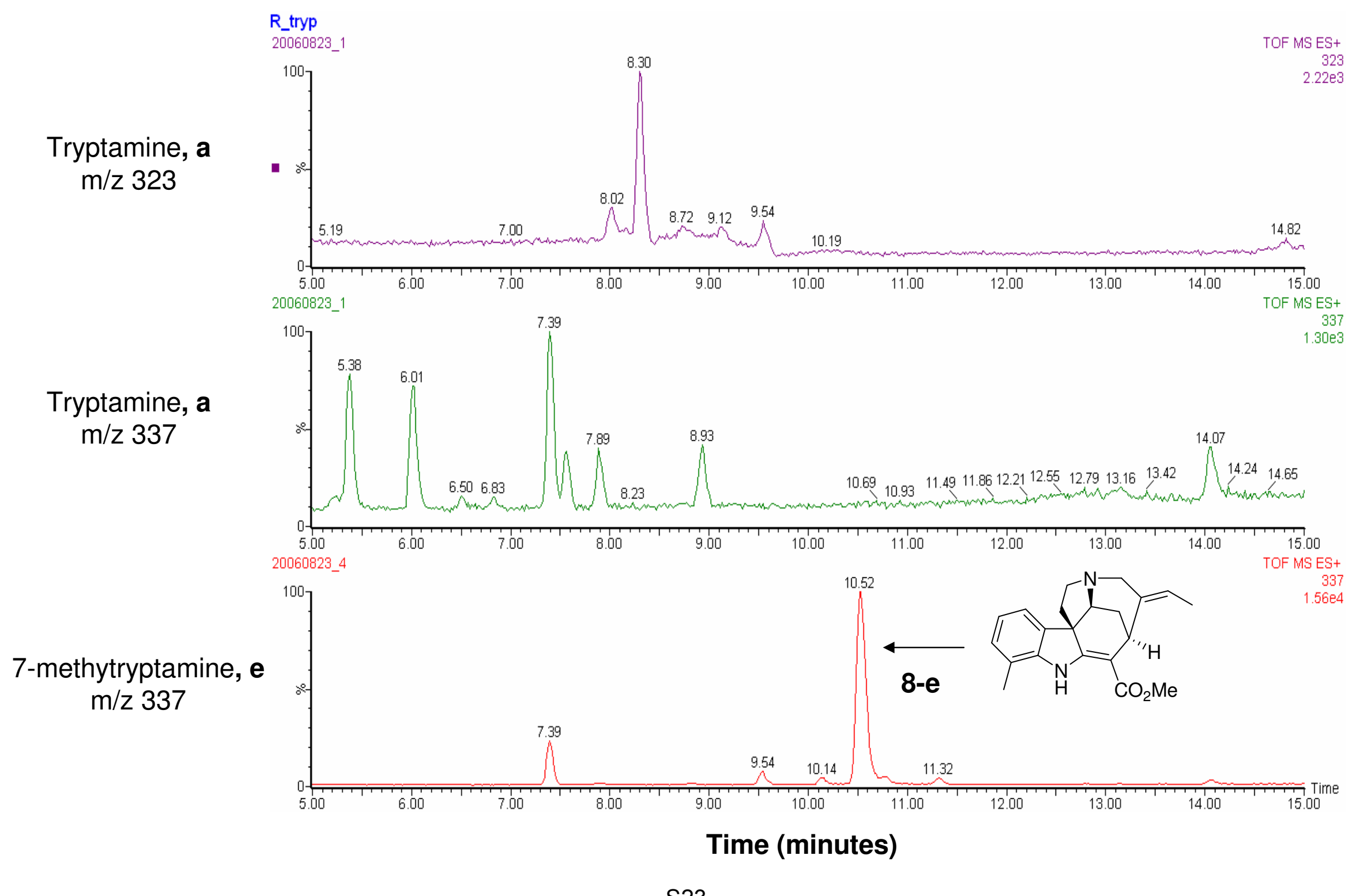




\subsection{2- 5-hydroxytryptmaine hairy root extract, serpentine}

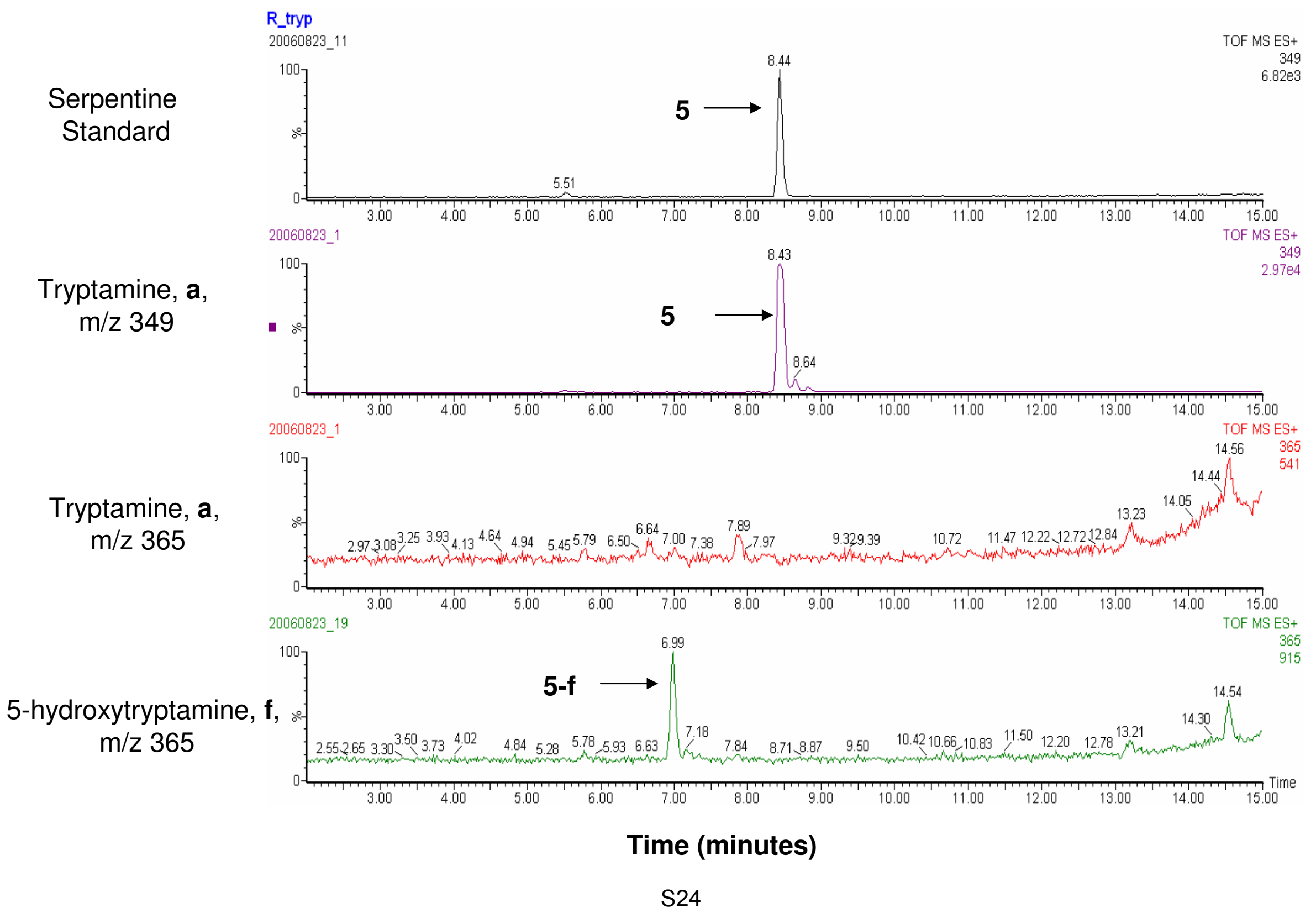




\subsection{3-5-fluorotryptamine seedling extract, vindolidine}

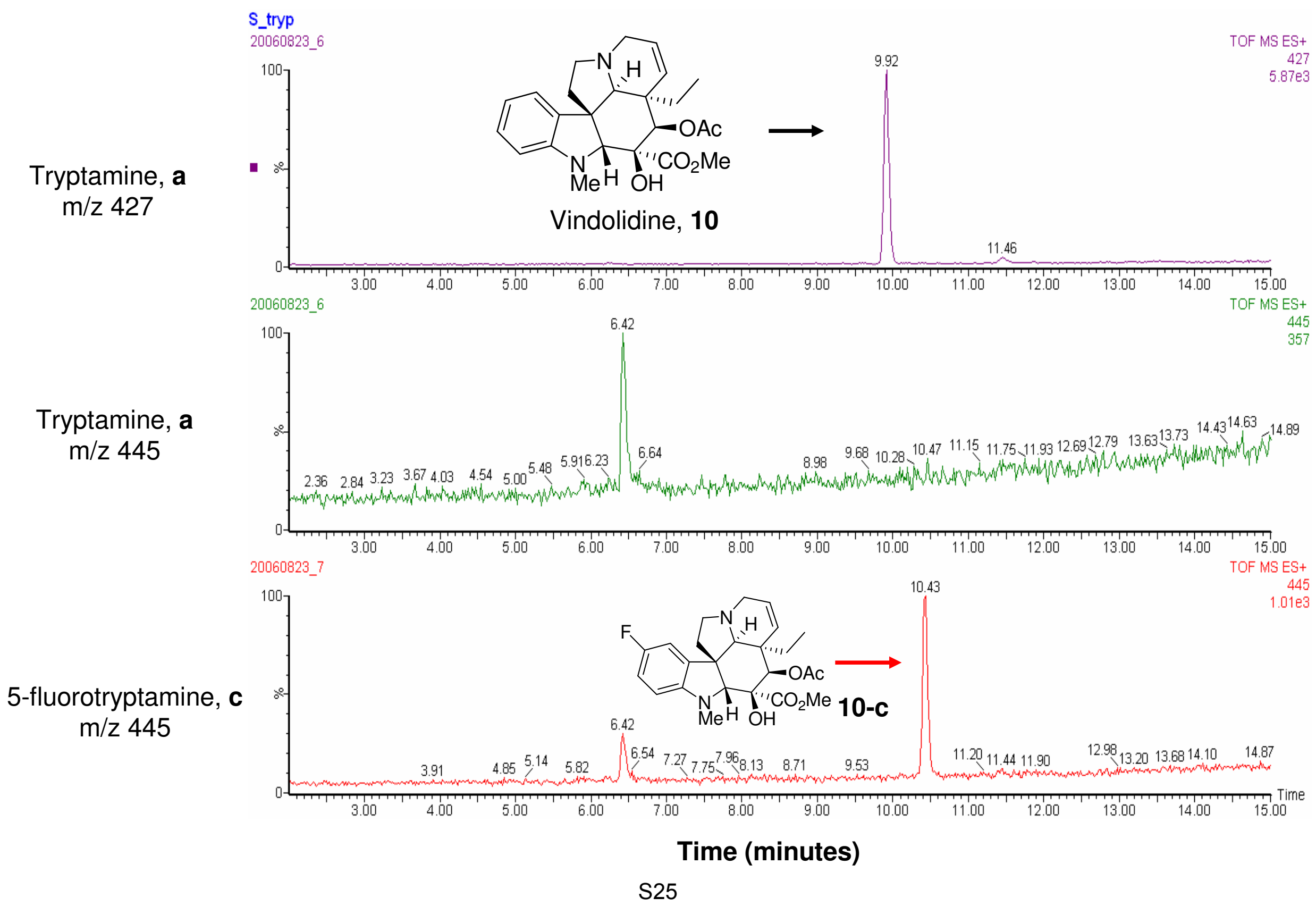




\subsection{4- 5-fluorotryptamine seedling extracts, vindoline}

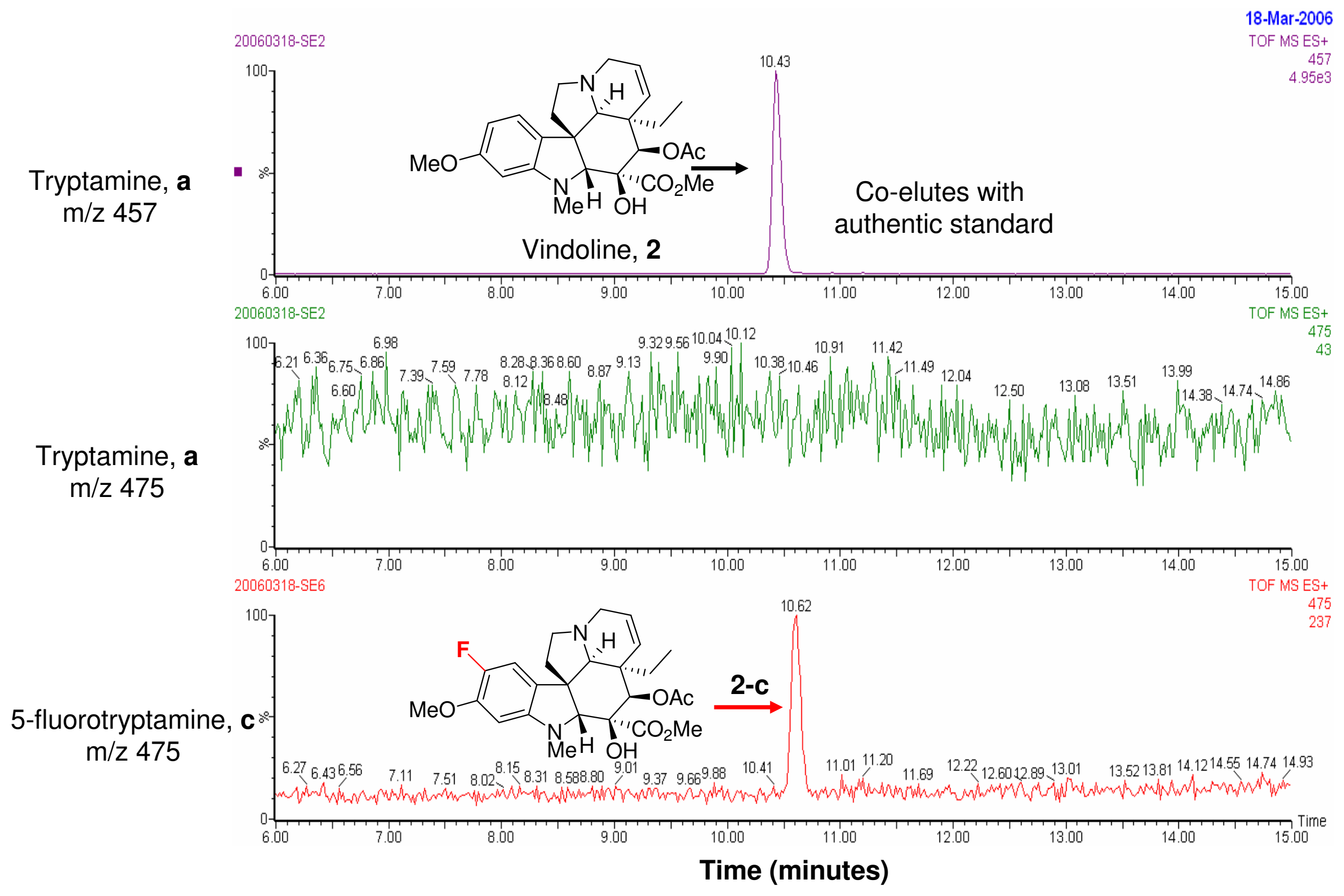




\subsection{5-5-fluorotryptamine seedling extract, ajmalicine}

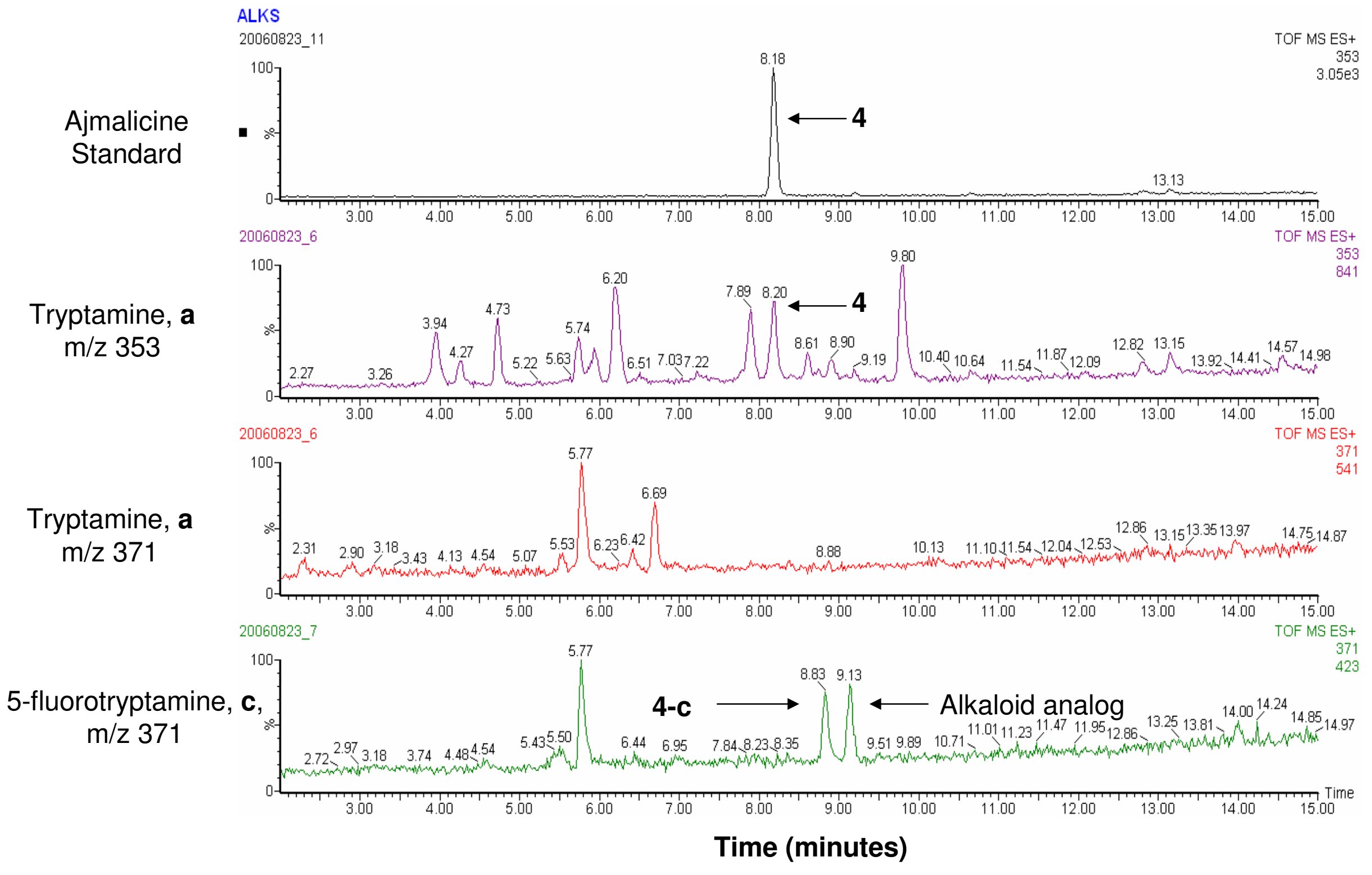




\subsection{6- 5-fluorotryptamine seedling extract, catharanthine}

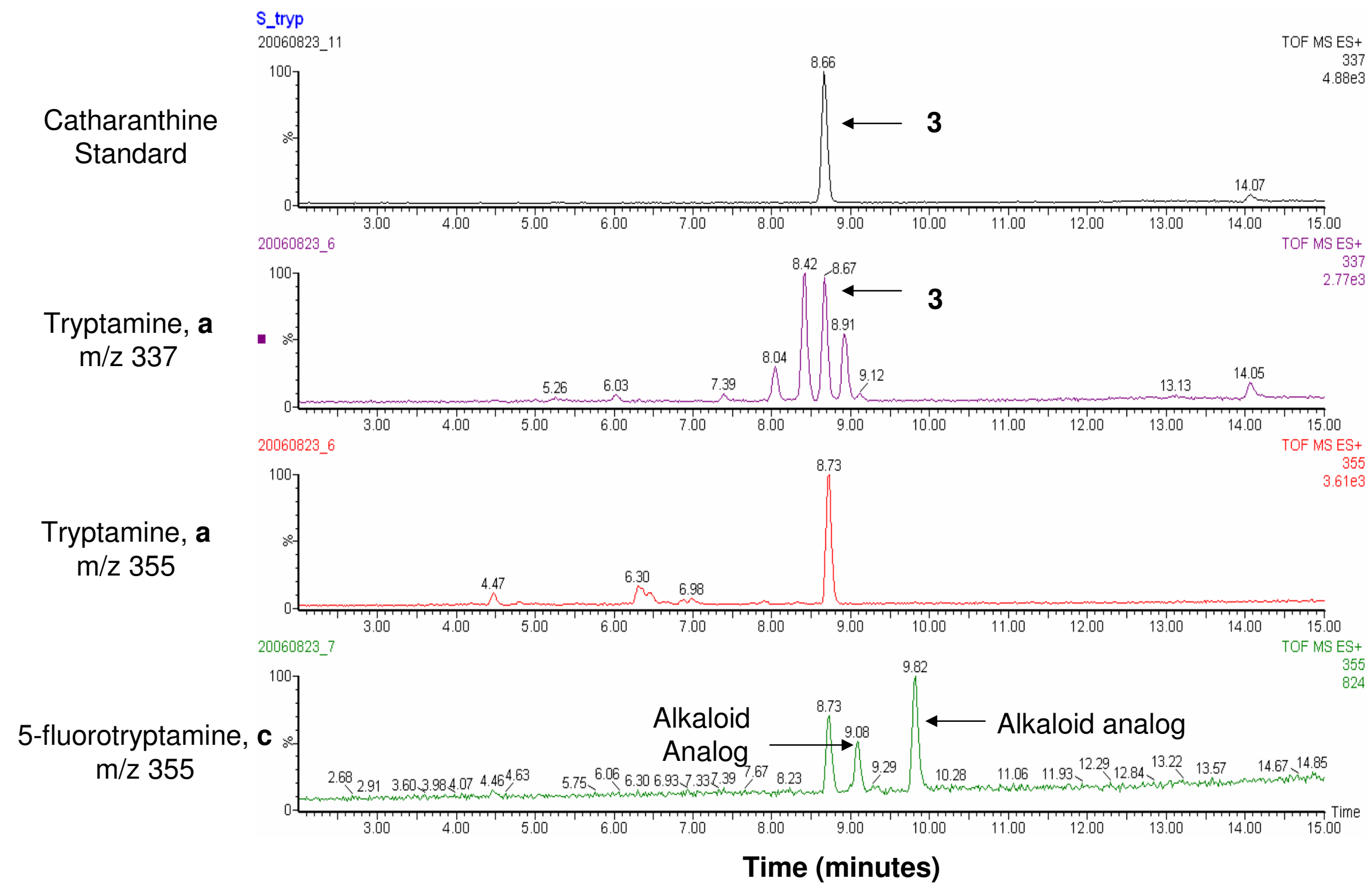




\subsection{7- 6-fluorotryptamine seedling extract, serpentine}

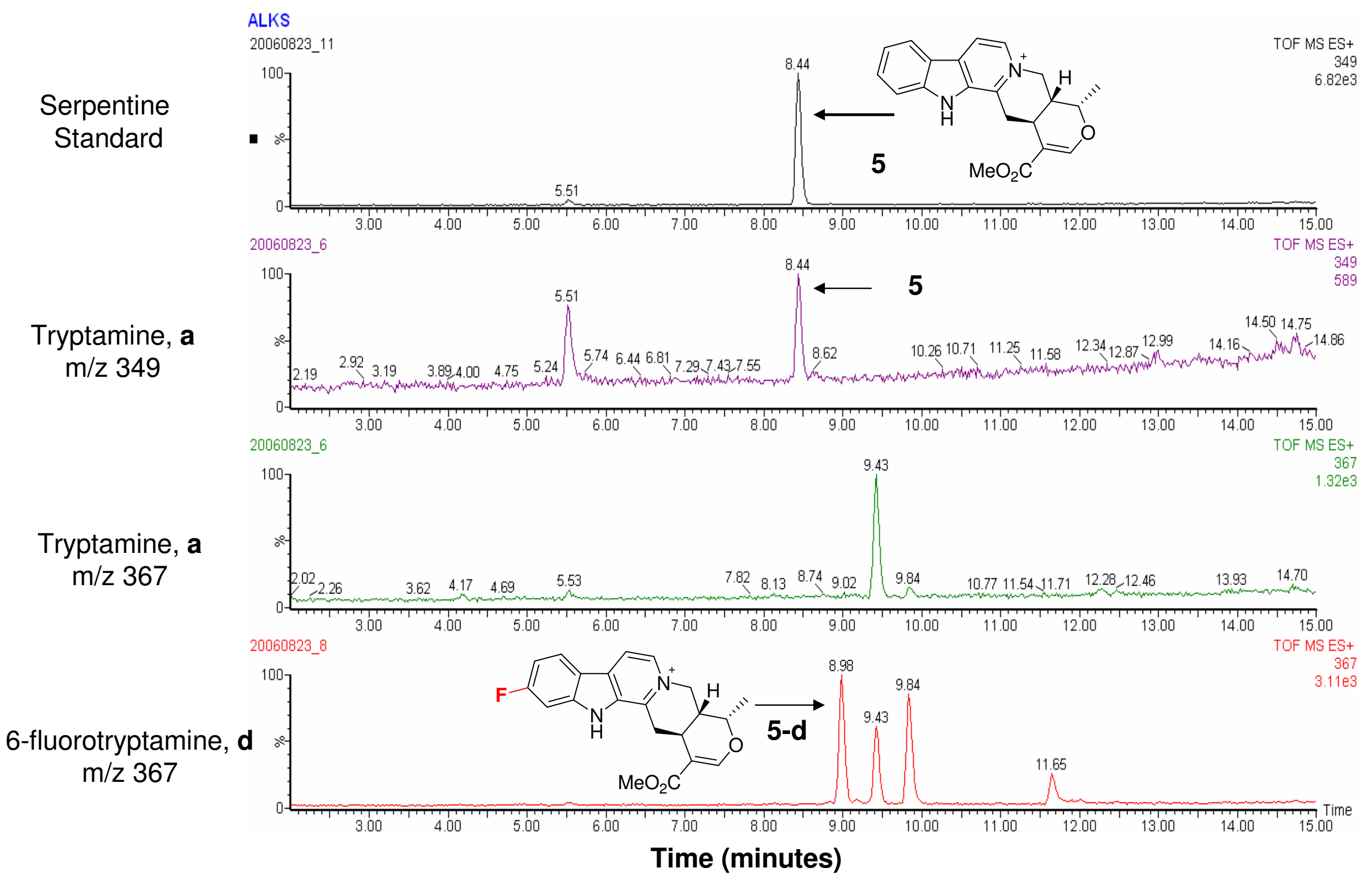




\subsection{8- 6-fluorotryptamine seedling extracts, vindolidine}

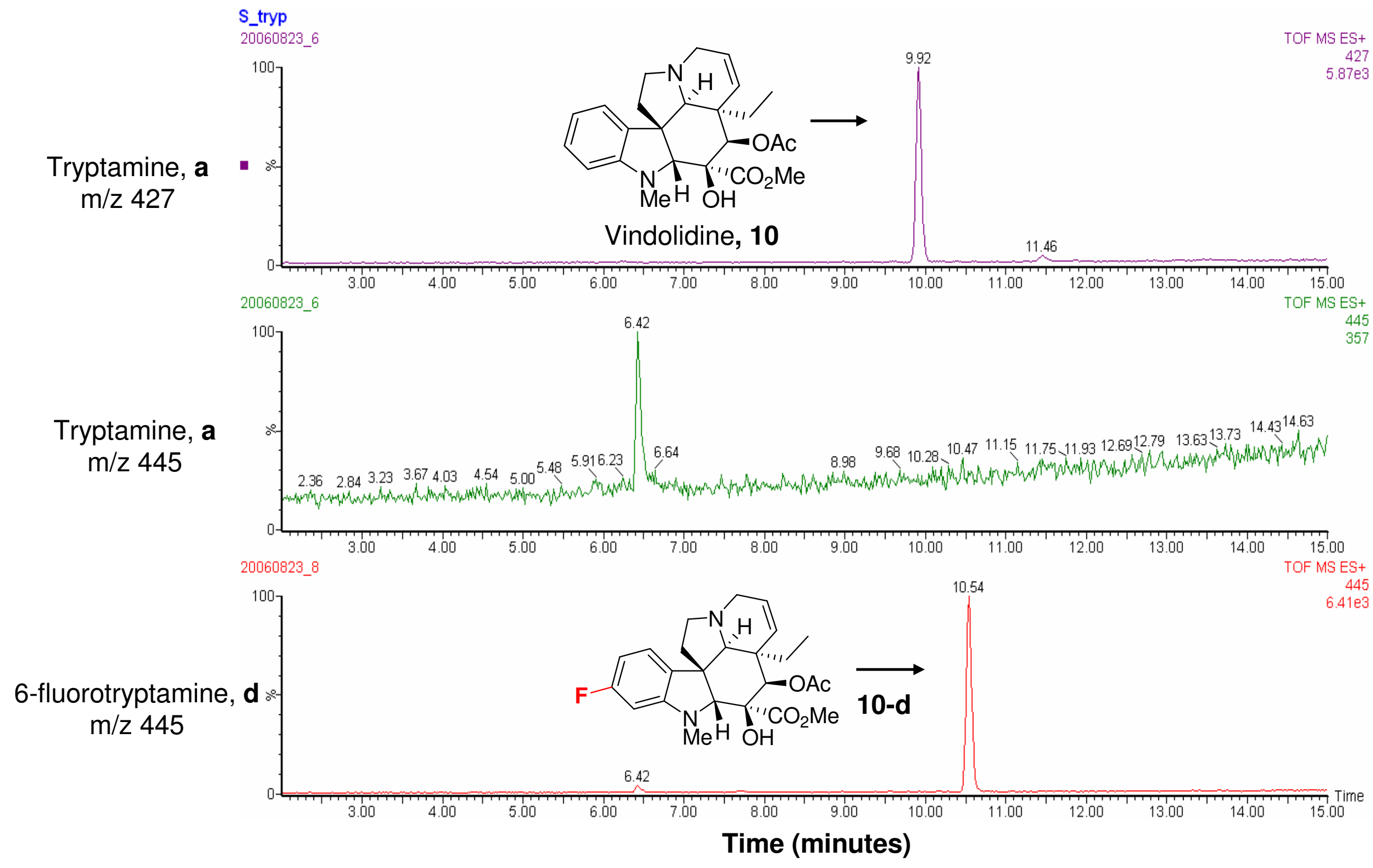




\subsection{9 - Mass fragmentation of 2, 10, 2-c, and 10-d. Fragment is result of loss of an acetate( $\mathrm{C} 2 \mathrm{H} 3 \mathrm{O} 2)$.}

Vindoline, 2

KD135

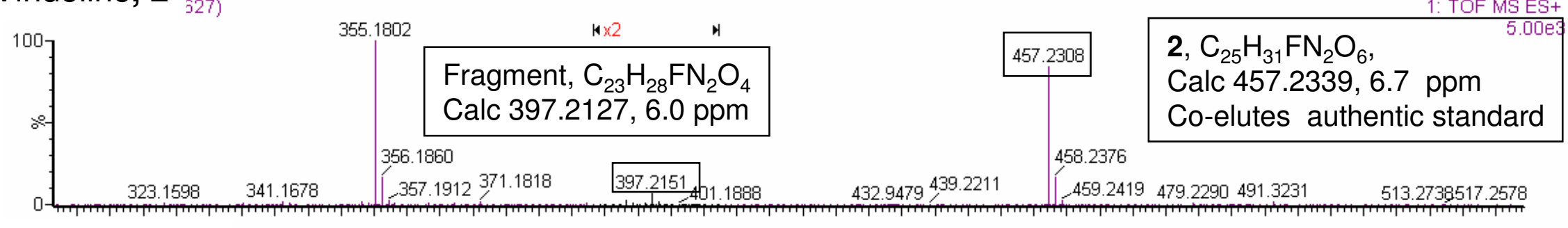

Vindolidine, 10

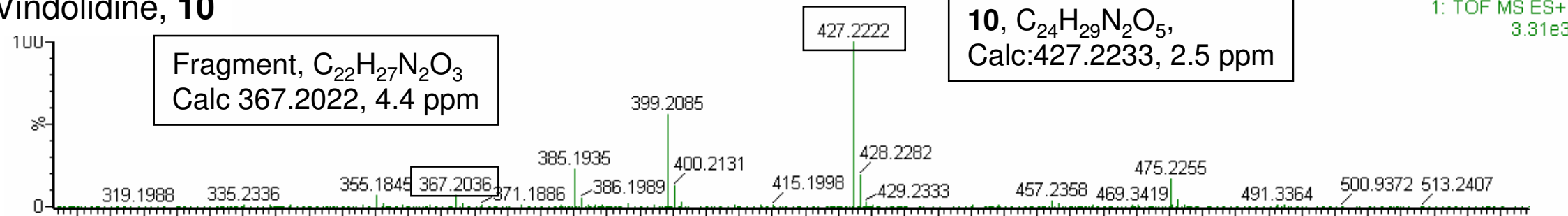

Fluorovindoline, 2-c

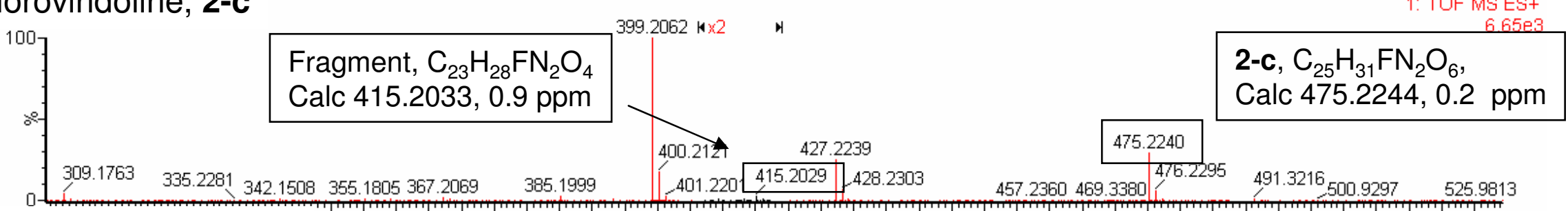

Fluorovindolidine, 10-d

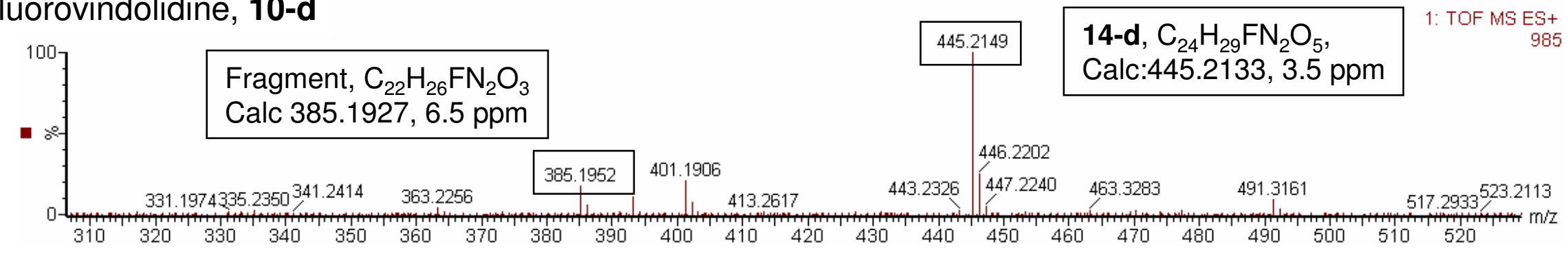




\subsection{0- 6-fluorotryptamine seedling extract, catharanthine}

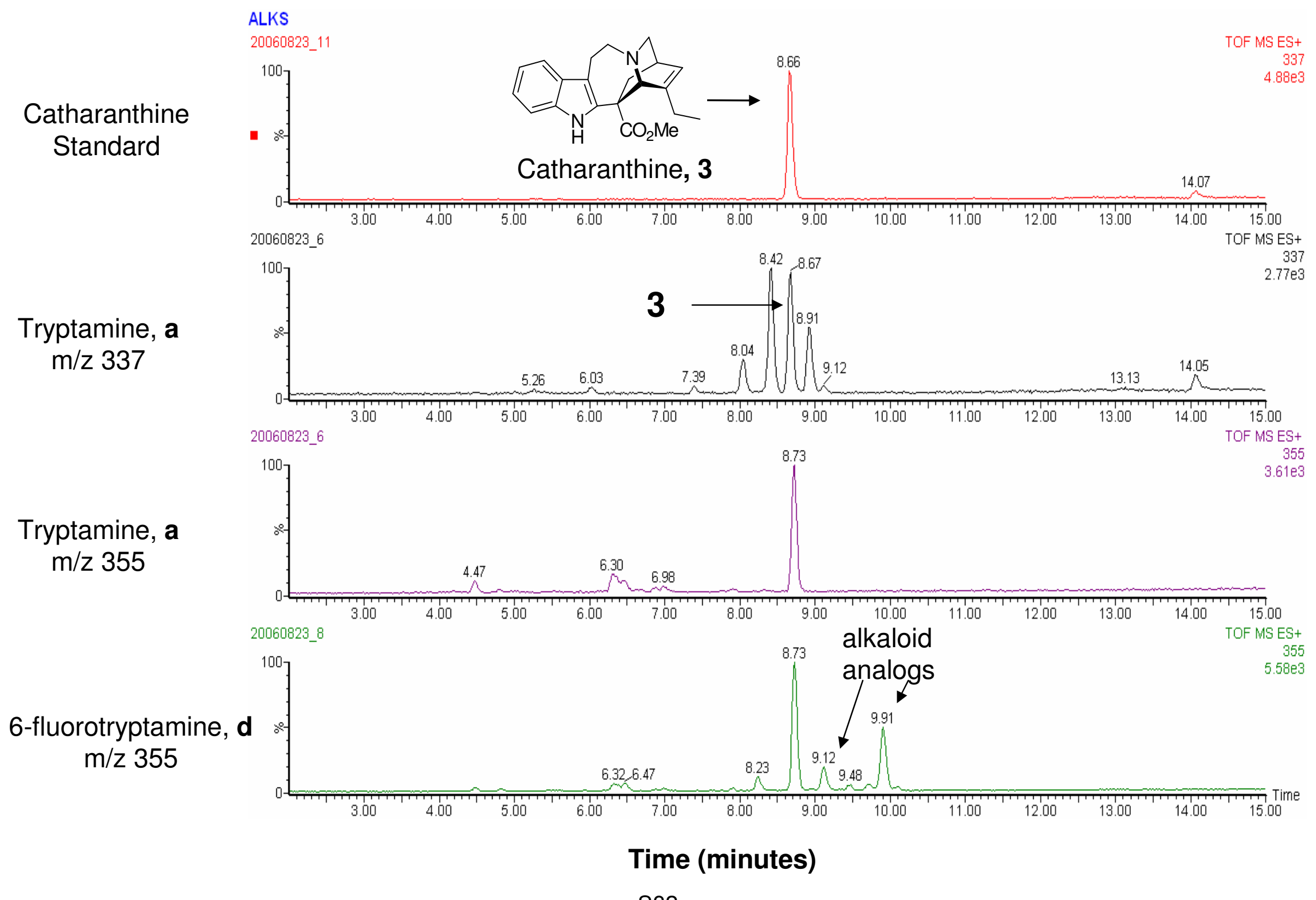




\subsection{1- 6-fluorotryptamine seedling extract, akuammicine}

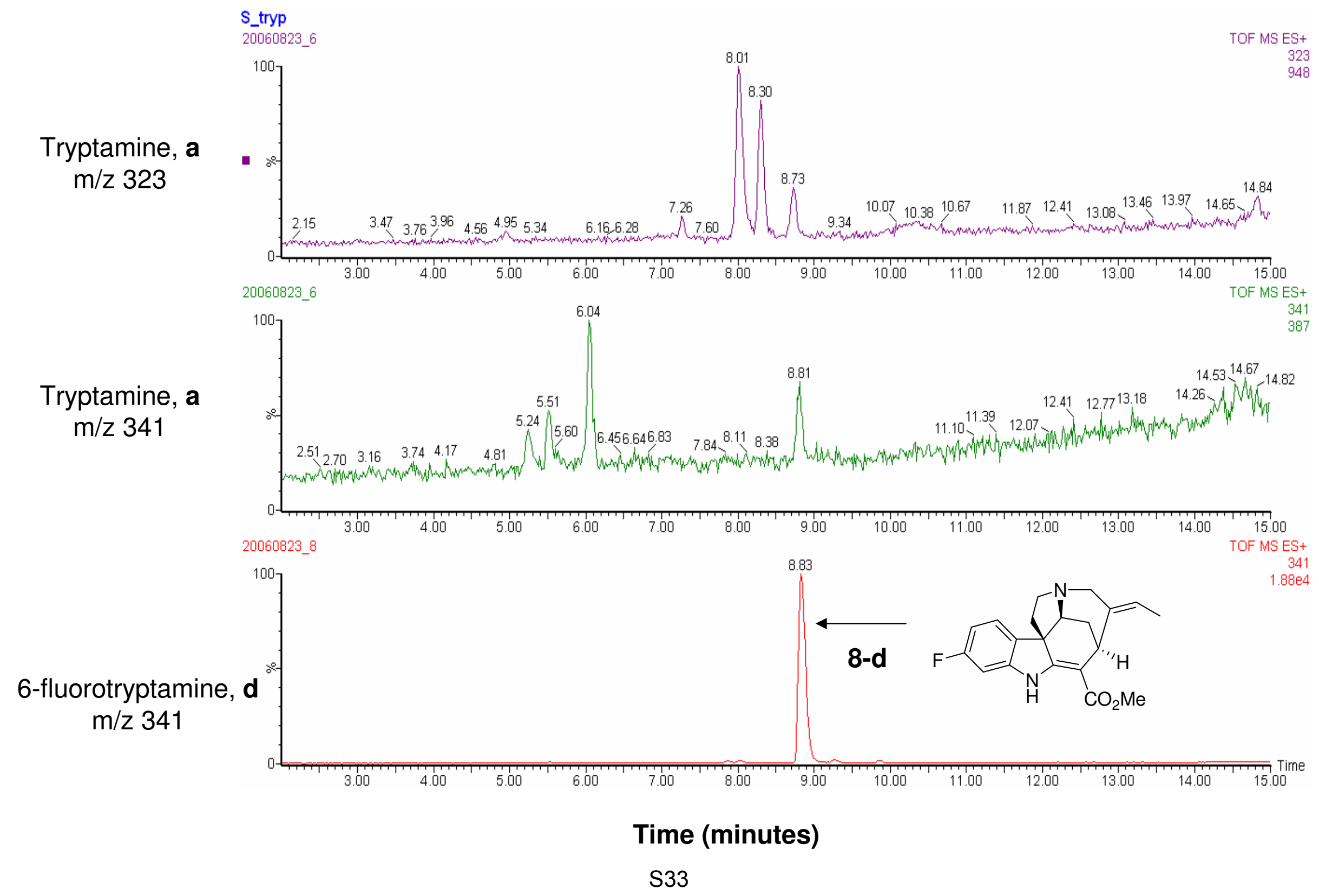




\subsection{2- 7-methyltryptamine seedling extract, serpentine}

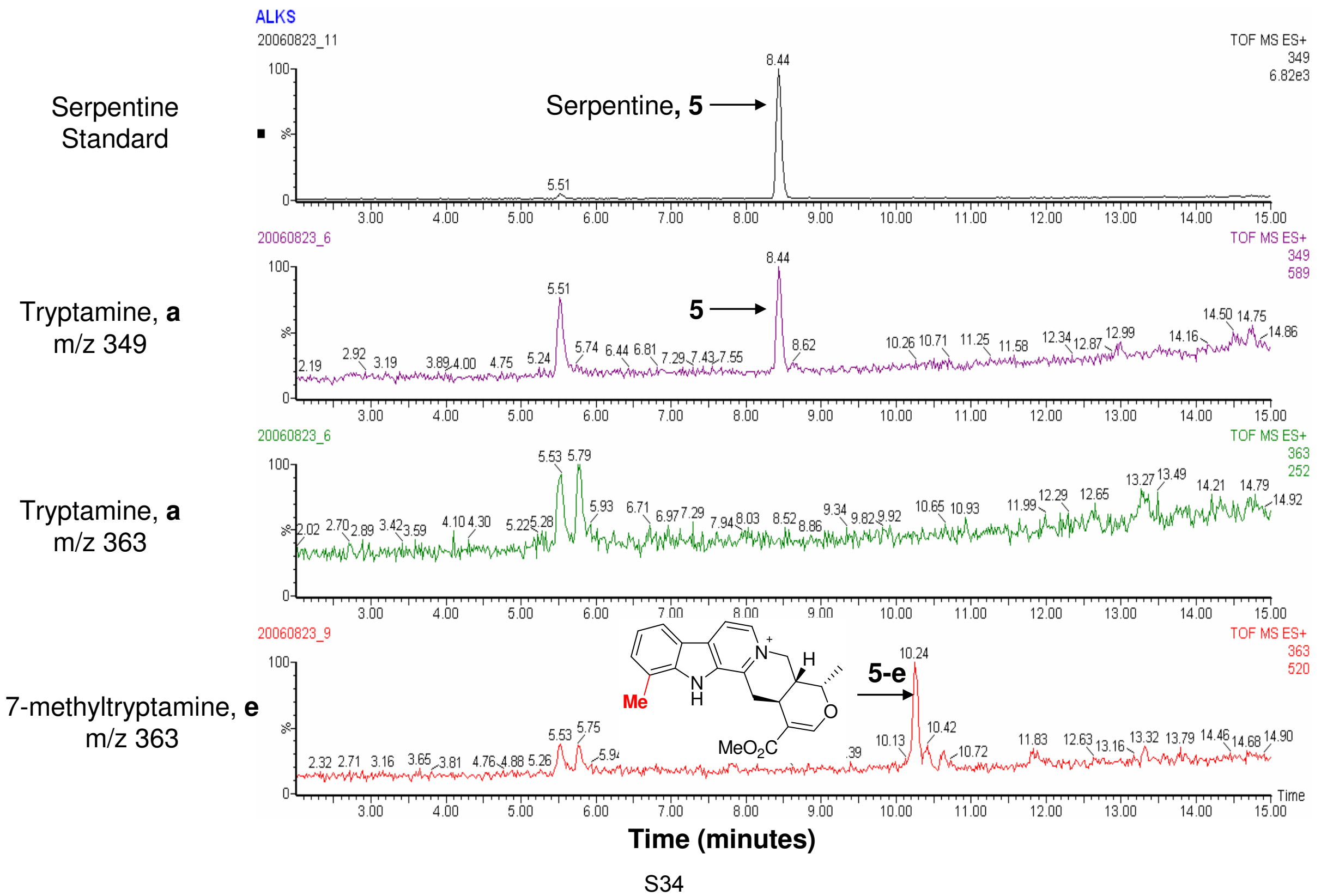




\subsection{3- 7-methyltryptamine seedling extract, ajmalicine}

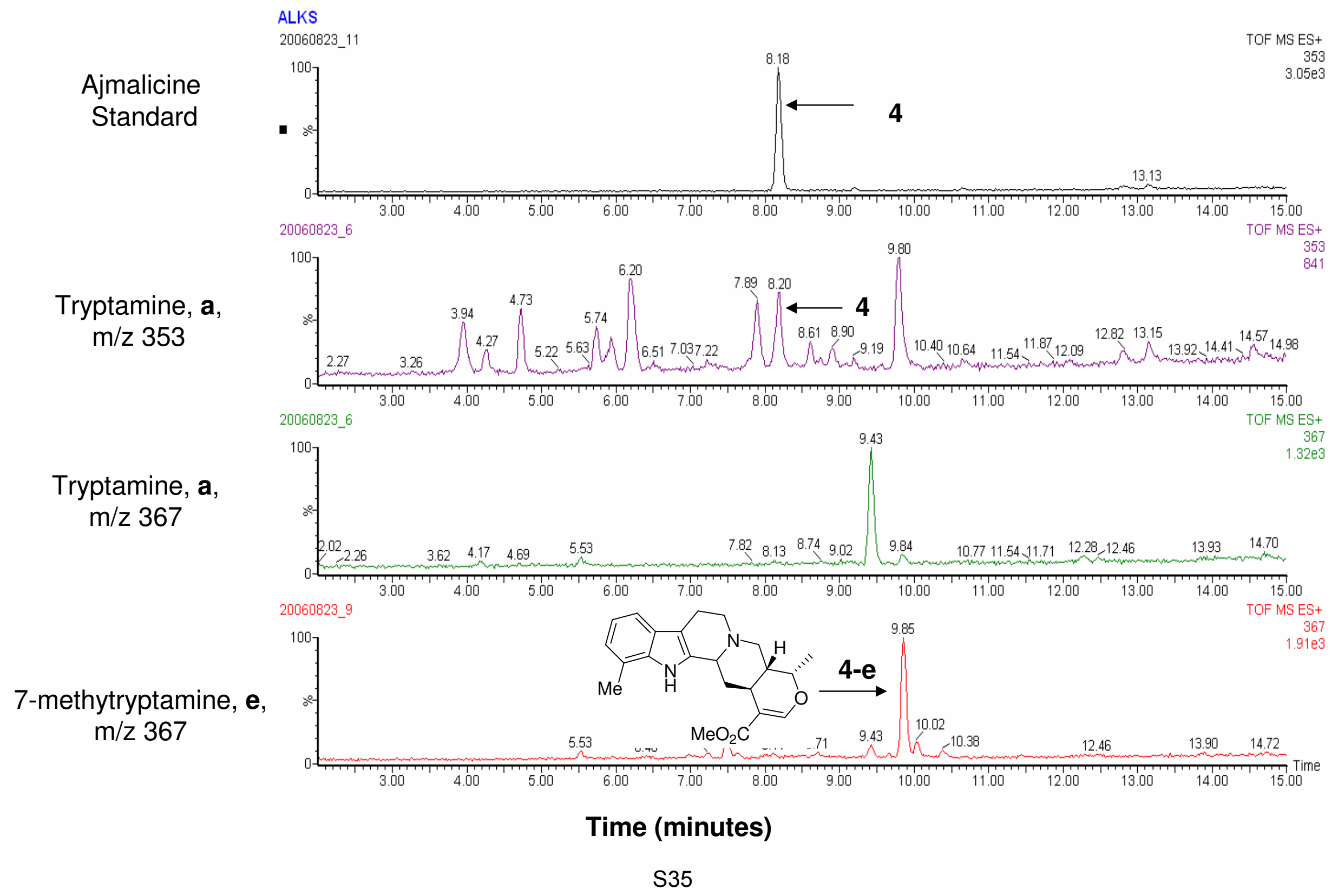




\subsection{4- 7-methyltryptamine seedling extract, yohimbine}

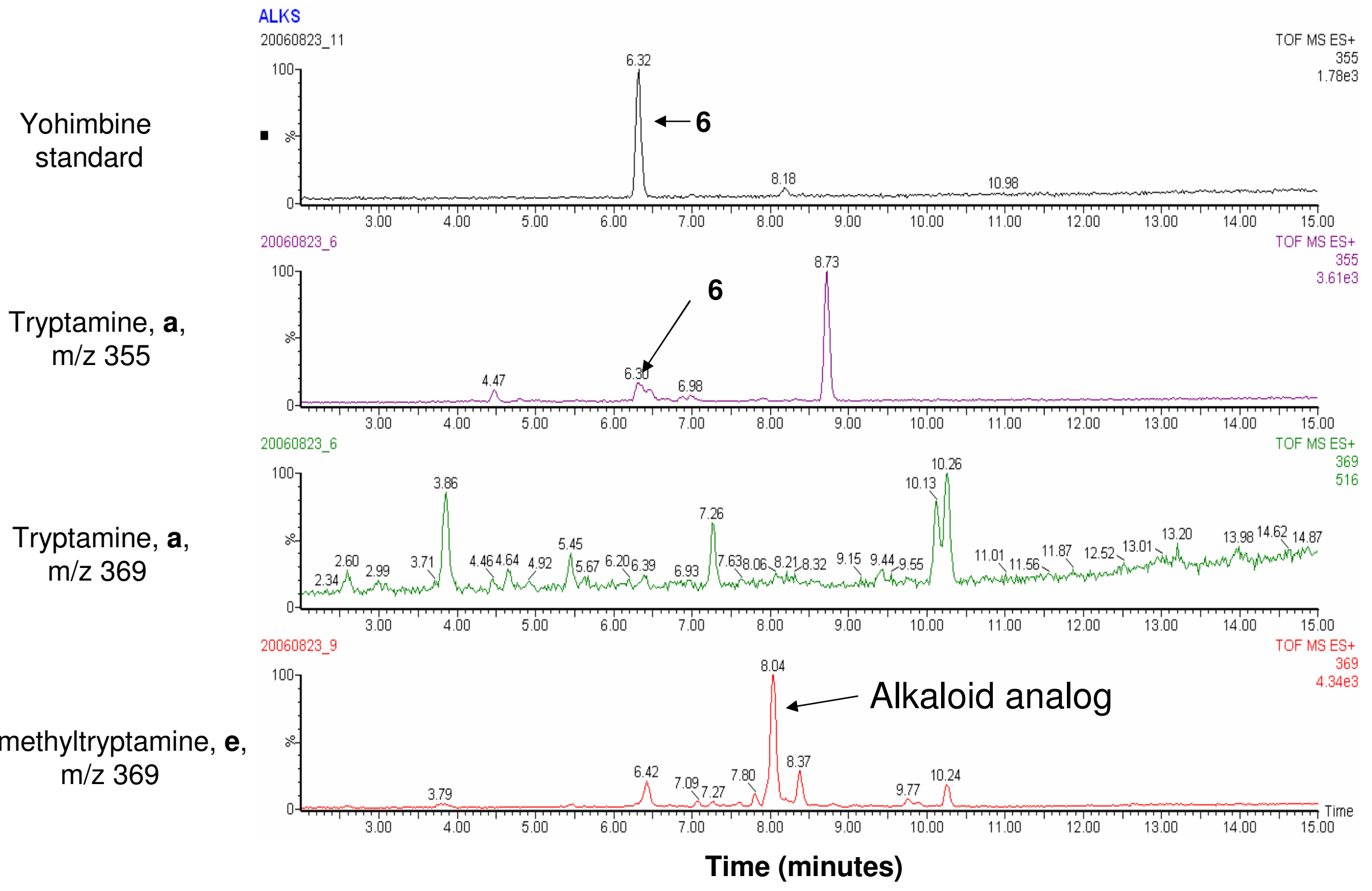




\subsection{5- 7-methyltryptamine seedling extract, akuammicine}

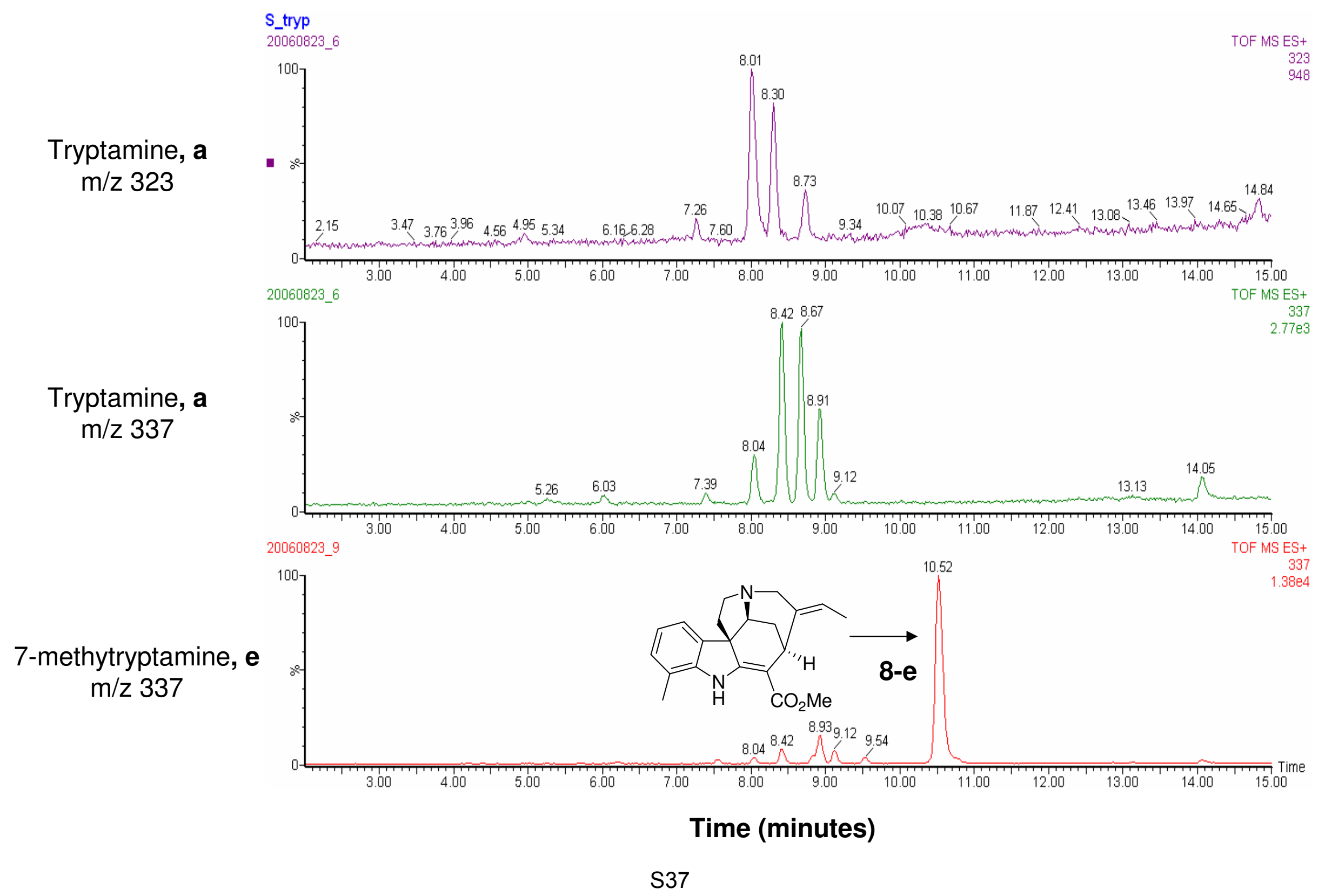




\subsection{6- 7-methyltryptamine seedling extract, catharanthine}

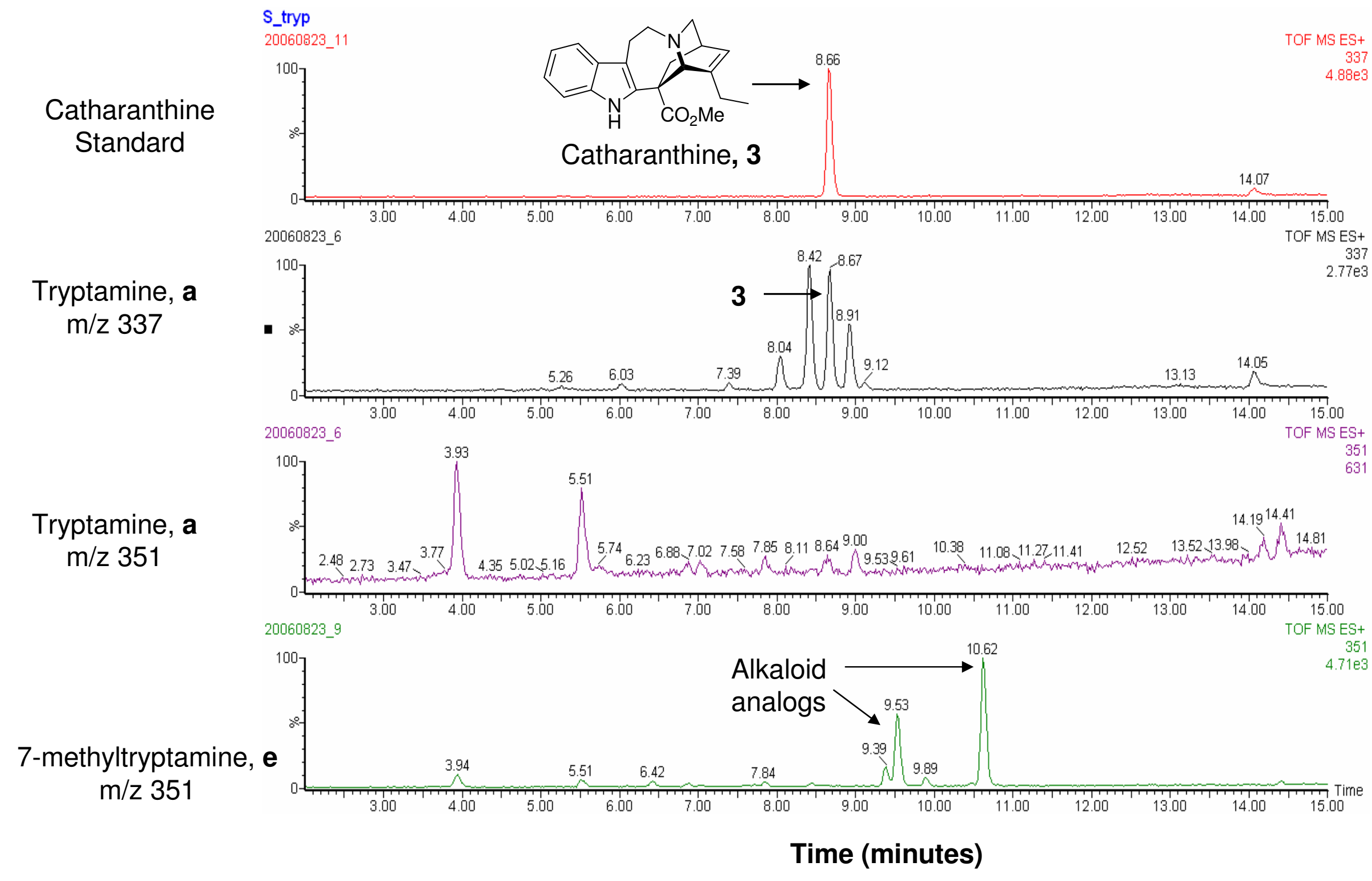

